\title{
Functional Anatomic Studies of Memory Retrieval for Auditory Words and Visual Pictures
}

\author{
Randy L. Buckner, ${ }^{1,2}$ Marcus E. Raichle,, ${ }^{1,2,3}$ Francis M. Miezin, ${ }^{1}$ and Steve E. Petersen ${ }^{1,3,4}$ \\ ${ }^{1}$ Department of Neurology and Neurological Surgery, Washington University School of Medicine, St. Louis, Missouri \\ 63110, ${ }^{2}$ Department of Radiology, Mallinckrodt Institute of Radiology, ${ }^{3}$ Department of Anatomy and Neurobiology, and \\ ${ }^{4}$ Department of Psychology, Washington University, St. Louis, Missouri 63105
}

Functional neuroimaging with positron emission tomography was used to study brain areas activated during memory retrieval. Subjects $(n=15)$ recalled items from a recent study episode (episodic memory) during two paired-associate recall tasks. The tasks differed in that PICTURE RECALL required pictorial retrieval, whereas AUDITORY WORD RECALL required word retrieval. Word REPETITION and REST served as two reference tasks.

Comparing recall with repetition revealed the following observations. (1) Right anterior prefrontal activation (similar to that seen in several previous experiments), in addition to bilateral frontal-opercular and anterior cingulate activations. (2) An anterior subdivision of medial frontal cortex [pre-supplementary motor area (SMA)] was activated, which could be dissociated from a more posterior area (SMA proper). (3) Parietal areas were activated, including a posterior medial area near precuneus, that could be dissociated from an anterior parietal area that was deactivated. (4) Multiple medial and lateral cerebellar areas were activated. Comparing recall with rest revealed similar activations, except right prefrontal activation was minimal and activations related to motor and auditory demands became apparent (e.g., bilateral motor and temporal cortex). Directly comparing picture recall with auditory word recall revealed few notable activations.

Taken together, these findings suggest a pathway that is commonly used during the episodic retrieval of picture and word stimuli under these conditions. Many areas in this pathway overlap with areas previously activated by a different set of retrieval tasks using stem-cued recall, demonstrating their generality. Examination of activations within individual subjects in relation to structural magnetic resonance images provided anatomic information about the location of these activations. Such data, when combined with the dissociations between functional areas, provide an increasingly detailed picture of the brain pathways involved in episodic retrieval tasks.

Key words: memory; positron emission tomography; prefrontal cortex; episodic memory; precuneus; pictures
Functional anatomic pathways involving prefrontal areas, anterior cingulate, and cerebellar areas have recently been implicated in long-term memory retrieval (Squire et al., 1992; Andreasen et al., 1995a; Buckner et al., 1995a; Haxby et al., 1996). Several of these areas, especially within prefrontal cortex, have been suggested to be specifically related to certain kinds of memory retrieval (Tulving et al., 1994b; Buckner et al., 1995a; Fletcher et al., 1995a).

One of the most consistent findings is that specific prefrontal areas become activated during the recollection of information from temporally unique events, a form of memory commonly referred to as episodic memory. Episodic memory retrieval differs from other forms of retrieval in that the unique context associated with a learned episode is accessed as part of the retrieval event (Tulving, 1983, 1985). Most notably, areas in right anterior prefrontal cortex have been commonly activated across several episodic retrieval tasks (Squire et al., 1992; Tulving et al., 1994a; Andreasen et al., 1995a; Buckner et al., 1995a; Grady et al., 1995; Haxby et al., 1996; Schacter et al., 1996). Other forms of retrieval,

Received Feb. 29, 1996; revised July 9, 1996; accepted July 15, 1996.

This work was supported by National Institutes of Health Grants NS06833, EY08775, HL13851, and Grant AG08377, the Charles A. Dana Foundation, and the McDonnell Center for the Study of Higher Brain Function. We thank Dacia Hunton, Maurice Makram, Len Lich, John Hood, Tom Videen, and the staff of the Cyclotron Unit for technical assistance, and Avi Snyder for help with the MRI data.

Correspondence should be addressed to Dr. Randy L. Buckner, MGH-NMR Center, 13th Street Building 149, Room 2301, Charlestown, MA 02129.

Copyright (C) 1996 Society for Neuroscience $0270-6474 / 96 / 166219-17 \$ 05.00 / 0$ including semantic memory retrieval, do not require access to contextual information. During semantic memory retrieval, facts or pieces of information are accessed without reference to when or where they were acquired. Most neuroimaging tasks examining semantic memory retrieval have reported minimal, if any, activation of right anterior prefrontal cortex (Petersen et al., 1989; Wise et al., 1991; Kapur et al., 1994; Raichle et al., 1994; Buckner et al., 1995b; Fletcher et al., 1995a; Klein et al., 1995; Martin et al., 1995; Grabowski et al., 1996).

The finding that brain pathways involving certain prefrontal areas may be activated by episodic memory retrieval has appealed to many researchers (Tulving et al., 1994b; Fletcher, 1995a; Haxby et al., 1996; Nyberg et al., 1996; Schacter et al., 1996). Part of the reason for this positive interest is past difficulty in finding a functional anatomic set of brain areas, or pathways, that might underlie episodic memory and set it apart from other forms of memory.

We too find this an appealing possibility (Buckner and Petersen, 1996). However, we also believe it is too early to draw strong conclusions. The initial findings have made a promising start by suggesting certain brain areas that may be involved in episodic retrieval, but it seems premature to conclude that these areas are components of a pathway generally dedicated to episodic memory retrieval.

What is needed are further careful analyses of a large spectrum of episodic memory retrieval tasks, as well as retrieval tasks 
outside the domain of episodic memory. The brain pathways used during each of these tasks should be specified as completely as possible. Then, by comparing data across tasks, brain areas and pathways differentially involved in tasks relying on episodic retrieval will become apparent.

We present positron emission tomography (PET) neuroimaging data from two episodic retrieval tasks involving pairedassociate recall. The data were examined thoroughly to reveal a detailed picture of the brain areas activated, as well as some of their locations in relation to structural magnetic resonance imaging (MRI) data.

\section{MATERIALS AND METHODS}

General design. Three goals were considered in constructing the tasks and methodology used in this study.

First, the cognitive tasks were designed to expand findings from our previous studies of episodic retrieval (Squire et al., 1992; Buckner et al., 1995a). These earlier studies examined stem-cued recall. To make the stem-cued recall task comparable to a different kind of memory also being studied in those experiments (priming), a compromise in design was allowed. Subjects were able to recall only half of the words in the episodic memory condition and were encouraged to guess responses. This created a possible confound. Subjects recalled words on some trials and guessed (generated) new words on other trials. The observed right anterior prefrontal activations may have been attributable to the alternation (or shifting) between strategies rather than the retrieval demands themselves (Buckner et al., 1995a; Swick and Knight, 1996). The present experiment removed this confound by constructing tasks that required only recall.

Second, the present study was designed to look at two slightly different kinds of episodic retrieval: recall of pictures and auditory words. This manipulation was done to address the question of whether episodic retrieval tasks use different areas to access specific types of information being retrieved. It seems quite possible that, in addition to brain areas recruited in common by episodic retrieval tasks, additional distinct brain areas may be activated to supply modality or content-specific information (for an example of this phenomenon in relation to semantic retrieval, see Martin et al., 1995). Examining data across tasks from different laboratories has already suggested that this may be the case for episodic memory (Buckner, 1996; Haxby et al., 1996). As a basis for this exploration, we previously conducted an experiment in which subjects viewed picture stimuli (Buckner et al., 1995c). Activations in visual cortex during picture viewing were identified and served as areas that might be activated during picture recall.

Finally, we used a procedure that allowed within-subject averaging in brain areas believed to be related to episodic retrieval. By combining such PET data with MRI data, we specified anatomic locations of brain activations related to episodic retrieval more precisely than has previously been possible.

Subjects. Fifteen participants ( 7 men, 8 women) were recruited from the local Washington University community. Subjects were ages $18-35$ $($ mean $=24.1)$, strongly right-handed as measured by the Edinburgh handedness inventory (Raczkowski et al., 1974), without any significant abnormal neurological history, and normal or corrected-to-normal in visual acuity. Participants' consent was obtained following guidelines of the Human Studies and Radioactive Drug Research committees of Washington University. One male subject was found to have an arachnoid cyst and was excluded from data analysis.

Apparatus. Emission and transmission measurements were made using a Siemens 953B-CTI scanner (Spinks et al., 1992) in three-dimensional mode with septa retracted. The 953B gathers 31 transverse slices with $3.38 \mathrm{~mm}$ between slices. However, because of poor signal-to-noise properties in the end slices attributable to the three-dimensional reconstruction, only slices 6 through 25 were analyzed. MRI data were obtained on a Siemens 1.5 Tesla Vision System.

During PET scans, ear plugs were inserted and a plastic face mask was molded to each subject's head to reduce movement (Fox et al., 1985). All stimuli were generated by an Apple Macintosh II computer using the Symantec Think C compiler. Visual stimuli were presented on a 14 inch Apple Hi-Res RGB monitor. Auditory stimuli were played through the computer using an externally amplified Sony Active Speaker System (SRS-88PC). Key-press responses were obtained using a custom-made, two-button keypad interfaced to an input-output board (GW Instruments, MacADIOS II). Voice onset latencies were obtained using a voice-activated relay (Gebrands, G134IT) fed into the same interface. Horizontal electro-oculograms (EOGs) were recorded using standard patch electrodes.

PET procedures. PET scanning activation methodology developed at Washington University was used (Fox et al., 1988; Mintun et al., 1989; Petersen et al., 1989).

Subjects laid on a flat bed and were positioned within the tomograph so that they could comfortably view a computer monitor placed $\sim 40 \mathrm{~cm}$ from their eyes. A lateral skull x-ray was taken to verify appropriate head alignment and identify markers to locate the position of the transverse plane intersecting the anterior and posterior commissures (AC-PC line) (Talairach and Tournoux, 1988). Two $10 \mathrm{~min}$ attenuation scans (one in each scanning position, see below) were obtained using a Germanium-68 source.

For the functional neuroimaging scans, O-15-labeled water (half-life $123 \mathrm{sec}$ ) was used as a blood-flow tracer and administered as an intravenous bolus injection. Ten $40 \mathrm{sec}$ scans were performed sequentially on each subject with each scan spaced $\sim 12$ min apart to allow nearly complete decay of the O-15 between scans. Each scan was acquired while the subjects performed a behavioral task (for task descriptions, see Behavioral procedures). Because blood flow increases are known to be a linear function of radiation counts for scans of $<1$ min duration, measurements of arterial blood radioactivity after bolus injection were not made (Herscovitch et al., 1983; Fox et al., 1984; Fox and Mintun, 1989). Rather, local radiation counts were used to estimate local blood flow. For simplicity, changes in tissue radioactivity are referred to as changes in blood flow and quantified in terms of PET counts.

The 10 scans were acquired in two different scanning positions for each subject ( 5 scans in each position) so that the entire brain was sampled. Without this procedure, dorsal and ventral areas of the brain would not be imaged because of the limited axial sampling in the three-dimensional mode $(\sim 7 \mathrm{~cm})$. The same set of five behavioral tasks was scanned in each position. This procedure, which we refer to as "indexing," results in uneven sampling across the brain. Across indexing positions, the middle portion of the brain gets considerable sampling because both positions overlap in this region. We took advantage of this property and biased the positioning to allow redundant sampling to occur in frontal and occipital areas thought to be most interesting for this study.

Images were reconstructed using filtered back-projection with a Butterworth filter (order $=5$, half frequency $=0.5$ cycles $/ \mathrm{cm}$ ). This filter results in images smoothed to $\sim 14 \mathrm{~mm}$ full width at half-maximum. All blood flow images were globally normalized by linear scaling to 1000 PET counts so that fluctuations in global flow and random variations in the amount of O-15 injected would not obscure local changes induced by task manipulations (Fox et al., 1987). Each image was transformed into standardized stereotaxic space based on the Talairach and Tournoux atlas (1988). Cubic voxels in the transformed images measured $2.0 \mathrm{~mm}$. Within the text, coordinates are reported in $x, y, z$ format (positive $x=$ right; positive $y=$ anterior; positive $z=$ superior).

To isolate local changes in blood flow, subtraction images were generated by subtracting blood flow data of one scan (REFERENCE TASK) from a second scan (TARGET TASK). Because the scans were done while different tasks were performed, the TARGET minus REFERENCE subtraction images reflected blood flow changes induced by the processing demands that differed between the two tasks. All subtraction pairs were screened for movement to reduce noise. Signal-to-noise properties of the subtraction images were increased by averaging data from several subjects together and/or by averaging within a single subject (Fox et al., 1984; Mintun et al., 1989).

Analysis of PET data: strict criteria. To identify activations and determine their reliability with a considerable degree of confidence, a replication approach was used (Corbetta et al., 1993; Buckner et al., 1995a,b; Hunton et al., in press). This approach is based on a simple assumption: reproducibility of activations across data sets is the best indication that an activation is not attributable to image noise or irrelevant, spurious factors (e.g., movement artifact, vessel artifact, etc.).

For each subtraction analyzed, data were divided into two separate sets. No image used as either the target or reference tasks overlapped between the two separate data sets. One of the two sets, referred to as the hypothesis-generating data set, was selected and analyzed first. The second, independent hypothesis-testing data set was placed aside for later analysis.

The hypothesis-generating data sets were examined to identify activations with the highest peak magnitudes (those $>50$ PET counts). Spherical regions $(14 \mathrm{~mm})$ were defined around each of these peak activations 
in the first data set and tested for replication in the second hypothesistesting data set. A one-sample $t$ test with a hypothesized mean of zero was used to assess the statistical significance in the second data set. This analysis was conducted to test across-data set reliability.

If an activation was found to replicate, an estimate of the location of that activation was determined using the combined data set. This is because the combined data set, rather than either of the subsets of data used in the replication analysis, provides the best estimate of the activation's true location.

Because a wide range of laboratories use methods based on thresholding approaches in single-summed data sets (often $t$ - or $Z$-score criterion), we also computed such values. $t$ values for the regions defined on the best estimates of the activation locations were determined using the entire data sample. Such $t$ values differ from the kind computed to obtain the $p$ values in the replication approach described above. The $t$ values computed here use the entire data sample, as opposed to half of the data, but do not test whether the values replicate. Thus, such $t$ values characterize the within-data set reliability (similar to the statistical parametric mapping approach) (Friston et al., 1991) (for discussion, see Frackowiak and Friston, 1995), but do not make as strong a statement about generalization to multiple data sets as is done with the replication approach.

Importantly, regions of activation that pass the across-data set reliability screen and have a high within-data set $t$ value can be considered with a great deal of confidence.

Analysis of PET data: lenient criteria. So as not to make Type II errors by establishing too stringent criteria, we also report as "tentative activation foci" peaks with magnitude $>50$ PET counts and $t>3.50$. These activations pass thresholding criteria applied in most published papers and are likely to reflect true activations. However, because these activations were not replicated using the approach described above, they should be considered with a lesser degree of confidence.

Several of the tentative activation foci, especially those in poorly sampled regions of the cerebellum, could not be tested using replication because of data set limitations. That is, because of our sampling procedure, duplicate data often were not collected in the most inferior and superior brain regions. When this occurred, the number of separate images was too few to provide for independent hypothesis-generating and -testing data sets.

Analysis of PET data: regions across conditions. For a limited number of activations demonstrated to be reliable using the strict criteria, regional cerebral blood flow (rCBF) was tracked across multiple task subtraction images. This allowed behavior of these regions to be better characterized.

Analysis of visual areas previously activated during picture viewing. Specific analyses were conducted to examine possible visual cortex activations during PICTURE RECALL and AUDITORY RECALL. These analyses were based on a previous study in which we examined visual areas activated during picture viewing (Buckner et al., 1995c). The picture stimuli used in this previous study were identical to the stimuli being recalled from memory in the present study.

Five visual regions were found to be differentially activated by picture viewing compared with word viewing (Buckner et al., 1995c). To test the hypothesis that regions activated during the perception of pictures might be reactivated during the recall of pictures from memory, $t$ tests were conducted to determine whether these five regions were activated more during PICTURE RECALL than during AUDITORY WORD RECALL, or whether these regions were activated in either RECALL task compared with REPETITION and/or REST (see Behavioral procedures). Spherical regions $(14 \mathrm{~mm})$ defined in the manner described earlier were used.

Analysis of PET data: within-subject analysis. Multiple subtraction pairs were generated within each subject for several of the task comparisons. This enabled the creation of averaged within-subject images with good signal-to-noise properties (Silbersweig et al., 1993; Buckner et al., 1996). These single-subject PET images were used to better localize the activations in relation to structural MRI data (see MRI procedures).

Using an automated procedure (similar to Hunton et al., in press), within-subject activations were identified if their peak magnitudes were at least 100 PET counts in magnitude and within $15 \mathrm{~mm}$ of the location observed in the averaged image. This criteria is conservative and may miss activations that are present at lower magnitudes (Type II error) or that represent extreme individual variability. However, the goal of this analysis was to localize predetermined activations within individual subject's anatomies. For this reason, it seemed appropriate to use conservative criteria to be certain of the activations that were identified, even if that meant failing to identify activations within several of the subjects.
MRI procedures. A Siemens MP RAGE three-dimensional scanning sequence was obtained to provide detailed anatomic information. In sagittal orientation, the TR was $10 \mathrm{msec}$, TE $4 \mathrm{msec}$, and the inversion time was $300 \mathrm{msec}$. Voxel size was $1 \times 1 \times 1.25 \mathrm{~mm}^{3}$.

The MRI images were fit into stereotaxic space by selecting multiple points $(>150)$ along the surface of the MRI brains and matching the surface marking points to a template surface derived from the Talairach and Tournoux (1988) atlas. The surface match was iterative and performed until the fit between the atlas space and the individual MRI brain was minimal, as determined by a least-mean square value (Snyder et al., 1994). Fit was verified by viewing a digital Talairach template superimposed on the MRI image. MRI data from each of the subjects were then summed to produce an averaged MRI image.

Behavioral procedures. Activity during different behavioral tasks was imaged. Four of the tasks are relevant to the present report: PICTURE RECALL, AUDITORY WORD RECALL, REPETITION, and REST. The subjects closed their eyes during these four tasks but had their eyes open for memory study conditions that took place before some of these tasks. Each task was repeated twice in each subject (for an explanation, see PET procedures). A fifth FIXATION task also was included to be compared with the REST task, but it is not discussed in this report.

For both RECALL tasks, subjects studied item pairs (e.g., horsemount) before the PET scan. Each pair was studied twice within a 16-pair list (4.5 sec between pairs). The last item pair was presented (on average) 4.5 min before the beginning of the PET scan. Then, during the RECALL PET scans, subjects heard the second members of the pairs and were instructed to verbally recall the first members. Subjects were instructed not to dwell on any single word cue and to go on to the next item if they felt they had made a mistake.

The two RECALL tasks differed in that for PICTURE RECALL, item pairs were picture-word pairs, whereas for AUDITORY WORD RECALL, the items were word-word pairs (Fig. 1).

Specifically, during study for PICTURE RECALL, which was not scanned, subjects were presented with line-drawn objects on the computer monitor ( $3.5 \mathrm{sec}$ duration). After each picture was present for $1 \mathrm{sec}$, the auditory word was played. Subjects were instructed to remember what the pictures looked like and which words were paired with them, with a strong emphasis on remembering what the pictures looked like.

During study for AUDITORY RECALL, which also was not scanned, subjects heard a word and then, after a $1 \mathrm{sec}$ delay, heard a second word. The instructions to the subjects paralleled PICTURE RECALL except subjects were told to pay careful attention to what each word sounded like.

During the test phase, which was scanned, subjects heard the second members of the pairs in both RECALL conditions (1 word every $3 \mathrm{sec}$ ). The test instructions differed slightly between the two RECALL tasks. For PICTURE RECALL, subjects were instructed to listen to the word cue and recall what the associated picture looked like and say aloud the name of that picture. For AUDITORY WORD RECALL, subjects were instructed to listen to the word cue and remember what the associated word sounded like and say aloud that word.

The reason for the particular design of the RECALL tasks was to create two recall situations, both of which involved identical stimulation and a common verbal response during the PET scans but differed with regard to the kind of information being retrieved.

Pilot data obtained from behavioral subjects $(n=8)$ suggested that performance on PICTURE RECALL would be $\sim 81 \%$ correct recall, whereas performance on AUDITORY WORD RECALL would be slightly lower at $73 \%$ correct recall.

As a further behavioral measure, a forced-choice recognition test (8-item pairs) was given after the PICTURE RECALL scan task. Stimuli were two exemplars of the same object (Fig. 2), one of which overlapped with the particular exemplar the subjects studied. Subjects were instructed to indicate, with a key press, which exemplar was studied, a decision requiring knowledge of the visual form of the object (Tversky and Sherman, 1975). Although this procedure does not directly assess whether subjects used visual form information during the PICTURE RECALL task itself, it did assess whether subjects were storing and had access to visual form information.

The first reference task was REPETITION; subjects heard words and simply repeated the words aloud. This task involved the same stimulation as RECALL and similarly involved a common verbal output. REPETITION, however, did not require retrieval from episodic memory. A REST reference task, in which subjects rested with their eyes closed, also was included to serve as a low-level reference condition.

Between PET scans, a brief task was conducted to calibrate the EOG 


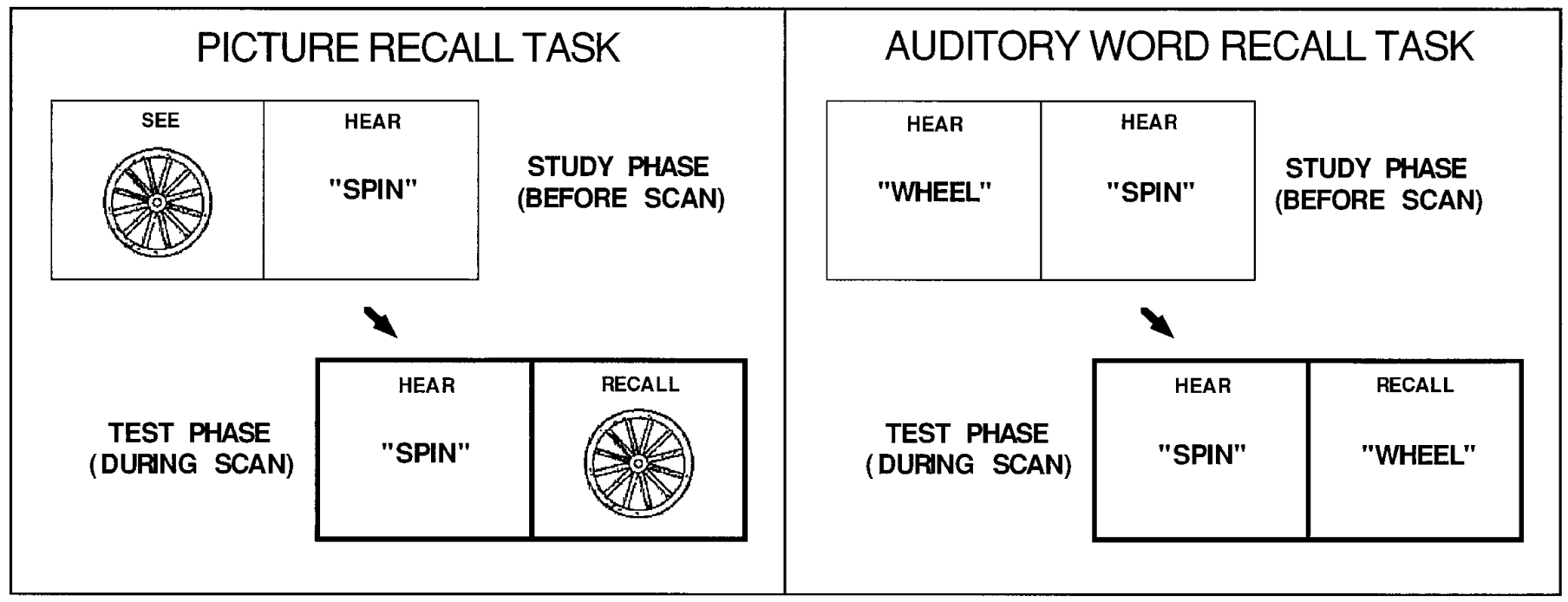

Figure 1. Diagrams illustrate the two different episodic memory retrieval tasks that were studied: PICTURE RECALL and AUDITORY WORD RECALL.

PICTURE RECOGNITION (AFTER PICTURE RECALL SCAN)
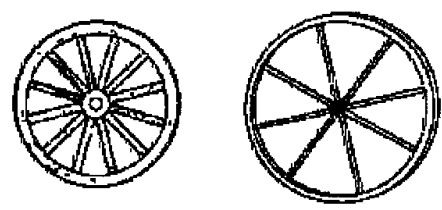

WHICH OBJECT WAS STUDIED?

Figure 2. An example of the stimuli used for the after-scan picture recognition task.

record. Subjects fixated and then moved their eyes back and forth between two locations.

Stimuli. Sixty-four line-drawn picture stimuli were selected from Snodgrass and Vanderwart (1980). Only pictures with extremely high naming agreement (mean $>90 \%$ ) were selected. For each picture, an associated verb was chosen resulting in 64 picture-word pairs used during PICTURE RECALL. Verbs were all unique and, where possible, not the most readily paired associate (e.g., horse-mount, mountain-scale, bed-make). A second parallel set of 64 word-word pairs was constructed such that the first members were the names of the picture objects in the previous set. This second set was used during AUDITORY RECALL.

All picture stimuli were digitally scanned and stored as Macintosh "PICT" resources. Auditory words were recorded in a male voice using a unidirectional microphone (Realistic 33-1073a). The words were recorded as Macintosh "snd" resources and edited to all be perceptually about the same loudness using SoundEdit (Macromind).

Picture-word and word-word pairs were divided into four lists of 16-item pairs. Lists were balanced for word frequency of the picture name and verb frequency (Kučera and Francis, 1967), and picture familiarity and picture complexity (Snodgrass and Vanderwart, 1980). Two additional lists of auditory nouns were constructed for REPETITION. These nouns were also names of Snodgrass and Vanderwart (1980) objects and matched all attributes to the nouns in the four RECALL task lists. Nouns were chosen for repetition, as opposed to verbs, to control for the possibility that accessing concrete nouns inherently evoked a certain level of visual recall or activity within visual cortex. Within this design, such processing-if it exists-is held constant between RECALL and REPETITION. Lists were counterbal- anced across the two RECALL tasks. Direct counterbalancing was not done across the RECALL and REPETITION tasks to allow the best picture-verb/word-word pairs to be used in the RECALL task.

\section{RESULTS}

\section{Behavioral results}

Table 1 shows RECALL performance. Subjects performed well in both RECALL tasks, with slightly better performance in PICTURE RECALL compared with AUDITORY WORD RECALL. A slight decrement in performance was noted as the study progressed (for both RECALL conditions), perhaps reflecting minimal fatigue or interference from the preceding items. An ANOVA revealed that both main effects were significant: $F_{(1,12)}$ $=5.79$ for recall condition and $F_{(1,12)}=7.87$ for order, both $p<$ 0.05 . The interaction was not significant $(F<1)$.

Voice onset latencies for RECALL indicated that responses in both PICTURE RECALL and AUDITORY WORD RECALL were significantly slower than during REPETITION (mean REPETITION latency was $539 \mathrm{msec}$ for the first presentation and 508 msec for the second), presumably reflecting the additional processing that is necessary for RECALL. Both effects were significant $(p<0.0001)$. Response latencies between PICTURE RECALL and AUDITORY WORD RECALL did not significantly differ (Table 1) $(p>0.2)$.

Subjects correctly recognized $91 \%$ of the pictures in the afterscan picture recognition test, indicating that they had encoded and stored the visual attributes of the studied pictures.

\section{PET results: activations identified based on strict criteria}

Analyses were first performed to identify brain areas related to the general episodic retrieval demands of the two RECALL tasks compared with the multiple reference control tasks. rCBF changes were identified in the RECALL minus REPETITION task subtraction (collapsed across PICTURE RECALL and AUDITORY WORD RECALL tasks) and similarly for the RECALL minus REST task subtraction.

The results of these two comparisons revealed many activations during RECALL (Tables 2 and 4; Fig. 3). Most consistent were: bilateral frontal-opercular cortex, in the anterior insula; anterior cingulate cortex, possibly including multiple areas; and an anterior 


\begin{tabular}{lllll}
\hline Table 1. Task performance & & & & \\
& Order & No. of responses & No. correct & $\%$ correct \\
Task & 1 & 14.5 & 14.3 & 89 \\
PICTURE RECALL & 2 & 13.8 & 13.6 & 851 \\
AUDITORY WORD RECALL & 1 & 13.6 & 12.8 & 843 \\
& 2 & 13.1 & 12.5 & 80 \\
\hline
\end{tabular}

Performance data obtained during PET scans. VOL, Voice onset latencies (mean value in msec).

region of the supplementary motor area (SMA). The location of the SMA activation shifted posteriorly when compared with REST (see section below).

Robust right anterior prefrontal activations were observed only in relation to REPETITION. When RECALL was compared with REST, the right anterior prefrontal activations were minimal (see section below). Several parietal activations including an area in posterior medial parietal cortex (near precuneus) showed activation (see section below). Finally, several cerebellar areas were activated across the comparisons, but most detected here likely are attributed to motor demands of the tasks, as they were not present in the RECALL minus REPETITION subtraction. However, a number of cerebellar areas were activated that appear to be related to the nonmotor aspects of the tasks, as was demonstrated using the lenient criteria.

Several areas were found to be deactivated during RECALL (i.e., more activated during the reference tasks than during the RECALL tasks; Tables 3 and 5). These included a medial orbital frontal area and a medial parietal area that was anterior to the increased activation described above (Fig. 4). In relation to REST, a number of highly robust decreases in visual areas were present, as were similarly robust decreases in somatosensory cortex (Fig. 3) (see section below).

To determine brain areas that differed between PICTURE RECALL and AUDITORY WORD RECALL, the two tasks were directly compared. Surprisingly, almost no rCBF differences were noted between them (no activations reached the strict criteria). A few areas reached the lenient criteria as described below, but none of these was in visual cortex.

\section{PET results: activations identified based on lenient criteria}

Tables 6, 7, 8, and 9 show additional activations identified by the lenient criteria for the RECALL minus REPETITION, RECALL minus REST, and PICTURE RECALL minus AUDITORY WORD RECALL subtractions. Absence of a table for a given comparison means that no additional activations met the lenient criteria.

\section{Behavior of right prefrontal cortex and comparison to other studies}

A reliable right anterior prefrontal activation was observed in RECALL minus REPETITION (Fig. 3). Because this area was localized close to the right prefrontal activation noted in our earlier studies (Squire et al., 1992; Buckner et al., 1995a), further analyses were performed to better characterize this region. Post hoc analyses found this region to be increased in either PICTURE RECALL or AUDITORY WORD RECALL when REPETITION was used as the reference task (mean $=49, \mathrm{SE}=12$ and mean $=58, \mathrm{SE}=13$, respectively). Compared with the REST

Table 2. Identification of rCBF increases in RECALL minus REPETITION using strict criteria

\begin{tabular}{|c|c|c|c|c|c|c|c|c|c|}
\hline \multirow[b]{3}{*}{ Brain area } & \multicolumn{5}{|c|}{$\begin{array}{l}\text { Data from replication analysis } \\
\text { (data set divided as described in text) }\end{array}$} & & & & \\
\hline & \multicolumn{4}{|c|}{ Data set No. 1} & \multirow{2}{*}{$\begin{array}{l}\text { Data set } \\
\text { No. } 2 \\
\text { Significance }\end{array}$} & \multicolumn{4}{|c|}{$\begin{array}{l}\text { Best estimate of location and } t \text { value } \\
\text { (from combined data set) }\end{array}$} \\
\hline & $x$ & $y$ & $z$ & Magnitude & & $x$ & $y$ & $z$ & $t$ value \\
\hline SMA & -3 & 15 & 47 & 102 & $p<0.05$ & -3 & 13 & $\mathbf{5 0}$ & 7.12 \\
\hline Anterior cingulate & -5 & 19 & 36 & 65 & $p<0.01$ & -5 & 17 & 34 & 5.55 \\
\hline Anterior cingulate & $-\mathbf{3}$ & 29 & 26 & 61 & $p<0.05$ & $-\mathbf{3}$ & 31 & 22 & 6.32 \\
\hline Posterior medial parietal & -1 & -71 & 38 & 53 & $p<0.05$ & -3 & -69 & 34 & 3.99 \\
\hline Anterior medial cerebellum & -9 & -65 & -10 & 57 & $p<0.05$ & -9 & -49 & -14 & 2.01 \\
\hline Left anterior insular & -39 & 15 & 6 & 60 & $p<0.05$ & -37 & 13 & 6 & 4.33 \\
\hline Left posterior parietal & -31 & -69 & 42 & 86 & $p<0.05$ & -31 & -73 & 38 & 4.13 \\
\hline Right anterior insular & 33 & 15 & 8 & 55 & $p<0.05$ & 31 & 15 & 2 & 3.81 \\
\hline Right anterior prefrontal & 29 & 47 & 14 & 66 & $p<0.01$ & 27 & 49 & 16 & 5.14 \\
\hline Right anterior prefrontal & 29 & 53 & -10 & 63 & $p=0.09$ & 29 & 59 & -8 & 6.46 \\
\hline Right prefrontal & 41 & 21 & 26 & 52 & $p<0.005$ & 39 & 23 & 28 & 3.83 \\
\hline Right lateral parietal & 33 & -59 & 40 & 52 & $p<0.005$ & 33 & -61 & 42 & 3.31 \\
\hline
\end{tabular}

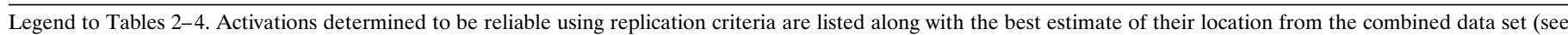

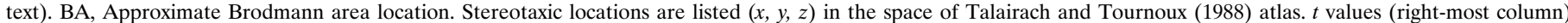

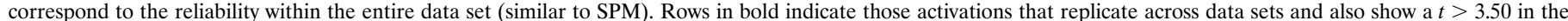
combined data set. Activations, shown in plain text, failed to meet one of the criteria or showed a trend. 


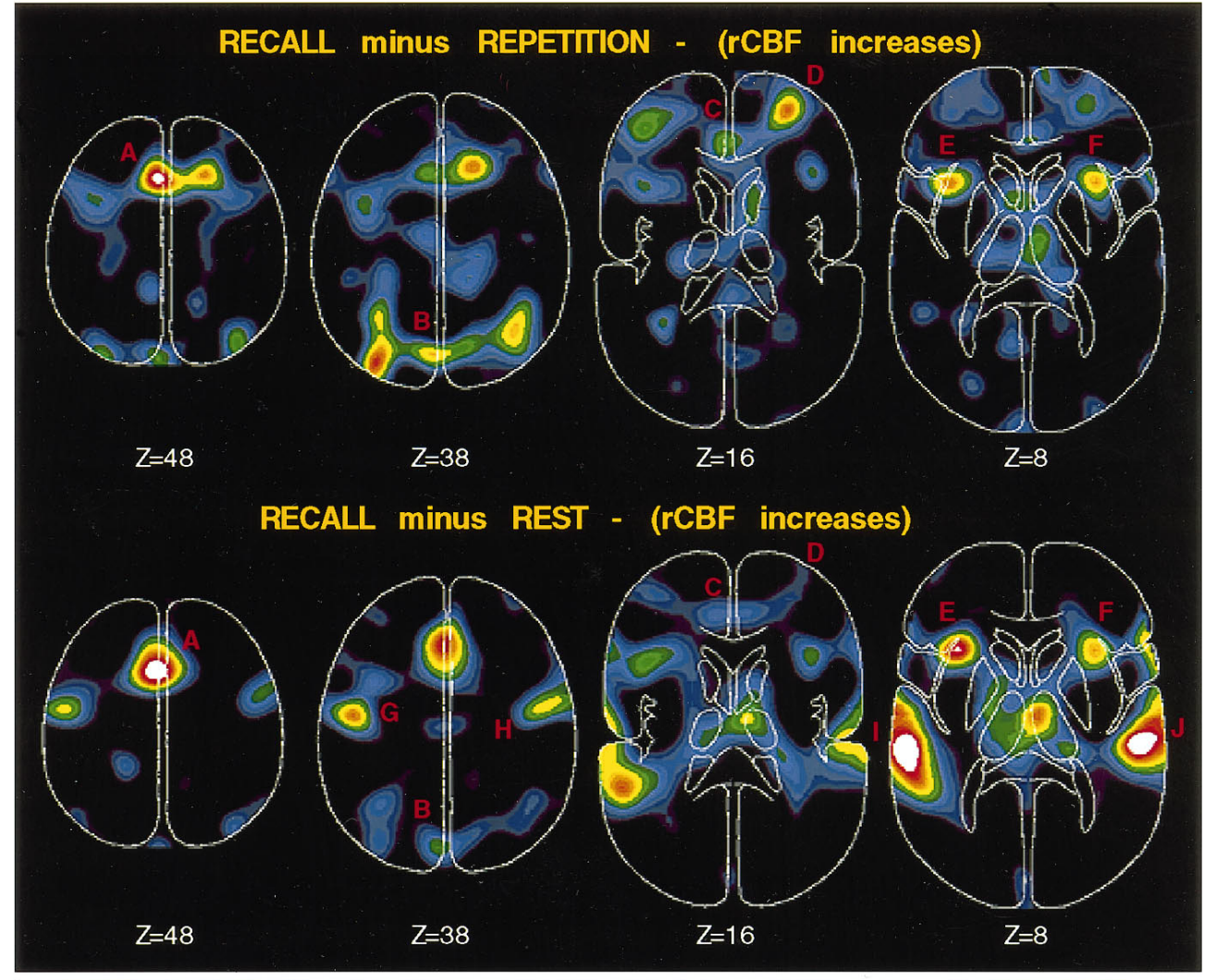

ICBF DECREASES in SOMATOSENSORY and VISUAL CORTEX (ALL TASKS ARE COMPARED TO REST)
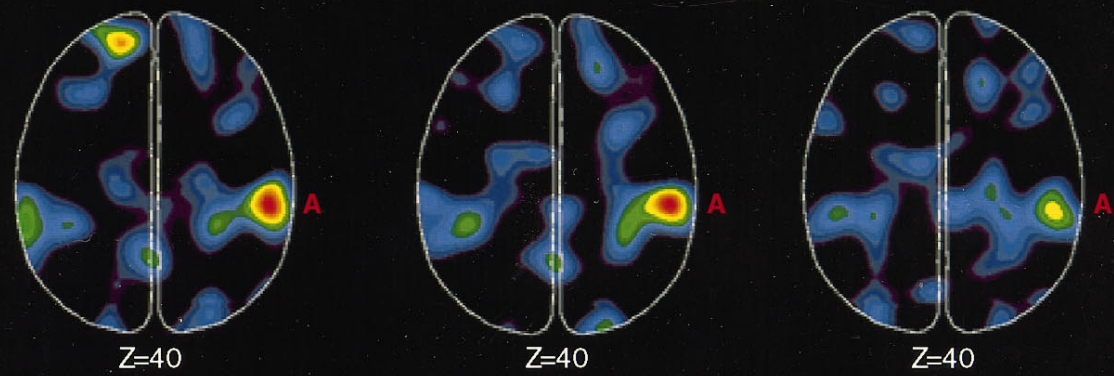

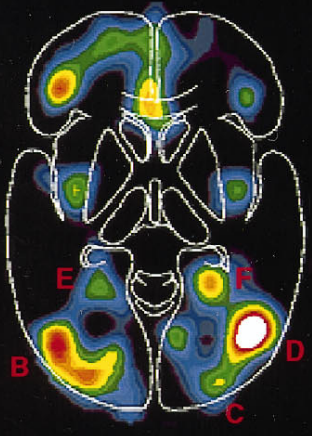

$Z=0$

AUDITORY WORD RECALL

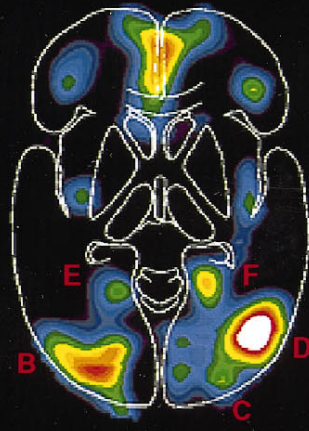

$\mathrm{Z}=0$

PICTURE RECALL

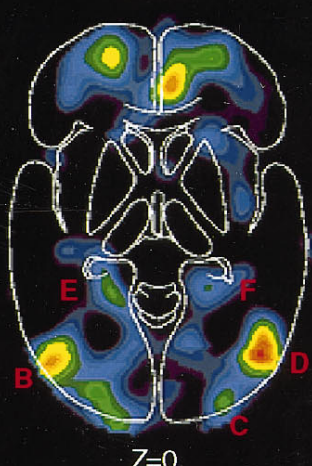

REPETITION
Figure 3. Horizontal sections show PET data from several of the subtraction images analyzed. All data are raw subtraction data displayed without threshold so that the quality of the image data can be observed. Brighter colors represent larger rCBF changes (peak $=$ white). Activations in the cerebellum are not shown but are listed in Tables 2, 4, and 6. Top, rCBF increases are shown (scaled to 70 PET counts). Several areas, only some of which are labeled, were found to be activated in RECALL minus REPETITION including SMA $(A)$, posterior medial parietal cortex $(B)$, anterior cingulate $(C)$, right anterior prefrontal cortex $(D)$, and bilateral frontal-opercular cortex $(E, F)$. RECALL minus REST (scaled to 100 PET counts) revealed many of the same activations with only minimal activation of right anterior prefrontal cortex $(D)$ and robust activation of motor cortex $(G, H)$ and auditory cortex $(I, J)$. Bottom, rCBF decreases are shown for all of the tasks involving auditory stimulation (AUDITORY WORD RECALL, PICTURE RE$C A L L$, and REPETITION) compared with REST. Robust rCBF decreases in somatosensory cortex $(A)$ (right $>$ left) and visual cortex $(B-F)$ are seen across all comparisons (scaled to -100 PET counts). reference task, however, rCBF increases were minimal (mean $=$ $11, \mathrm{SE}=14$ and mean $=9, \mathrm{SE}=15$, respectively). Consistent with this, a rCBF decrease was noted in REPETITION minus REST (mean $=-48, \mathrm{SE}=17$ ). This particular pattern of activation was similar to the results obtained in Buckner et al. (1995a), in which stem-cued recall, compared with a low-level fixation reference task, showed only a small right anterior prefrontal activation compared with a robust activation observed when stem cued-recall was compared with a more constrained stem-completion reference task. 
Table 3. Identification of rCBF decreases in RECALL minus REPETITION using strict criteria

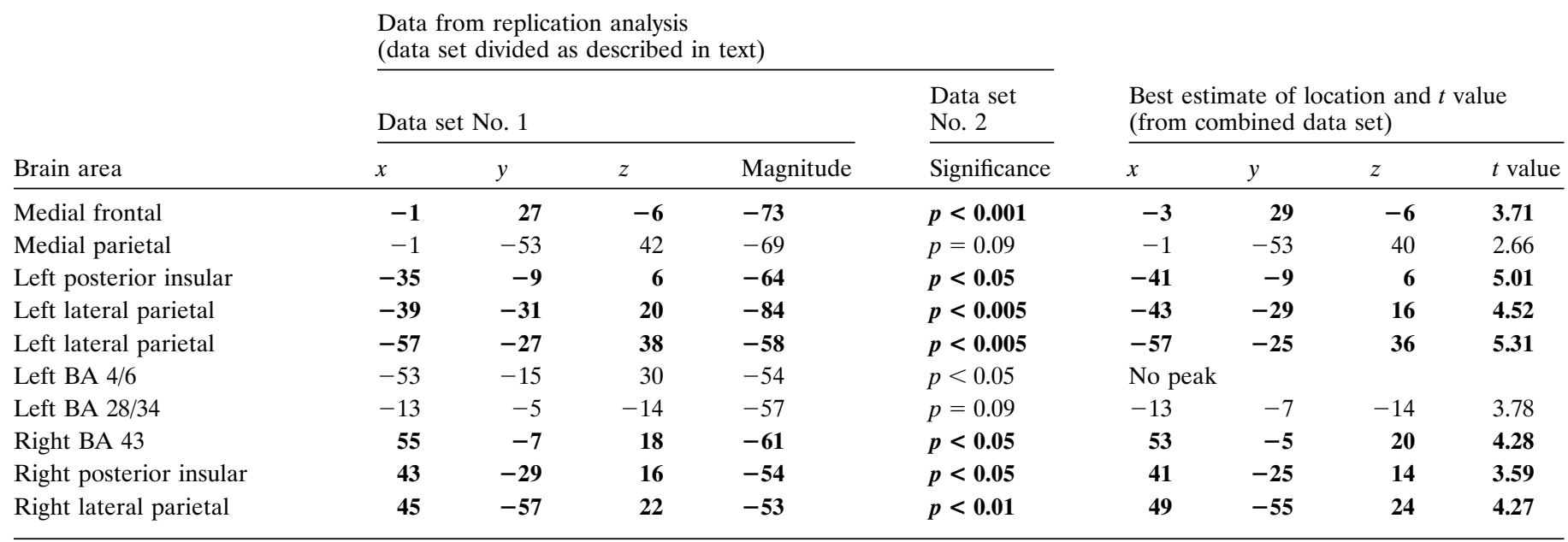

See legend to Table 2 .

\section{Behavior of medial-parietal cortex}

RECALL compared with either reference task revealed $\mathrm{rCBF}$ increases in a posterior medial parietal area (Tables 2, 4) and $\mathrm{rCBF}$ decreases in an anterior medial parietal area [Table 3; a rCBF decrease was noted against REST at $-3,-53,42$, but just missed the magnitude cutoff (46 PET counts)]. The fact that these two areas showed rCBF change in opposite directions suggested that they were dissociable. To establish this more definitively, rCBF was quantified across tasks for a region defined on the averaged location of the peak rCBF increase and for a region defined on the averaged location of the peak rCBF decrease. The locations were $-3,-72,37$, and -2 , $-53,41$, for the posterior and anterior regions, respectively. $\mathrm{rCBF}$ was tracked across multiple task comparisons for these regions and shown in Figures 4 and 5.

The posterior region, near precuneus, showed $\mathrm{rCBF}$ increases for both RECALL tasks compared with either of the reference tasks, with no $\mathrm{rCBF}$ change between the two reference tasks. The second more anterior region showed the exact opposite behavior: $\mathrm{rCBF}$ was decreased in RECALL compared with either reference task.

\section{Separation of pre-SMA and SMA}

Activation of an anterior division of the medial frontal wall was noted in the RECALL minus REPETITION subtraction (Fig. 3, Table 2). This area, which might be termed pre-SMA (Picard and

Table 4. Identification of rCBF increases in RECALL minus REST using strict criteria

\begin{tabular}{|c|c|c|c|c|c|c|c|c|c|}
\hline \multirow[b]{3}{*}{ Brain area } & \multicolumn{5}{|c|}{$\begin{array}{l}\text { Data from replication analysis } \\
\text { (data set divided as described in text) }\end{array}$} & & & & \\
\hline & \multicolumn{4}{|c|}{ Data set No. 1} & \multirow{2}{*}{$\begin{array}{l}\text { Data set } \\
\text { No. } 2 \\
\text { Significance }\end{array}$} & \multicolumn{4}{|c|}{$\begin{array}{l}\text { Best estimate of location and } t \text { value } \\
\text { (from combined data set) }\end{array}$} \\
\hline & $x$ & $y$ & $z$ & Magnitude & & $x$ & $y$ & $z$ & $t$ value \\
\hline SMA & -5 & 7 & 54 & 82 & $p<0.001$ & -3 & 7 & 52 & 6.97 \\
\hline Anterior cingulate & -3 & 25 & 38 & 54 & $p<0.01$ & -1 & 23 & 38 & 4.73 \\
\hline Posterior medial parietal & -1 & -75 & 40 & 56 & $p=0.05$ & -3 & -75 & 40 & 2.59 \\
\hline Anterior medial cerebellum & -1 & -39 & -14 & 73 & $p=0.0 .5$ & -1 & -41 & -22 & 3.30 \\
\hline Left anterior insular & -31 & 19 & 8 & 99 & $p<0.005$ & -33 & 19 & 4 & 5.21 \\
\hline Left prefrontal & -59 & 15 & 26 & 59 & $p<0.05$ & -59 & 15 & 26 & 4.91 \\
\hline Left primary motor & -43 & -13 & 40 & 67 & $p<0.01$ & -45 & -11 & 40 & 6.18 \\
\hline Right cerebellum & 35 & -63 & -22 & 75 & $p<0.05$ & 29 & -63 & -22 & 4.31 \\
\hline Right lateral cerebellum & 51 & -55 & -22 & 65 & $p<0.01$ & 49 & -55 & -22 & 4.35 \\
\hline Right posterior cerebellum & 19 & -85 & -24 & 67 & $p=0.05$ & No $p$ & & & \\
\hline Right primary motor & 55 & -5 & 38 & 54 & $p=0.08$ & 47 & -7 & 38 & 4.63 \\
\hline Right superior temporal gyrus & 53 & -23 & 8 & 98 & $p<0.005$ & 53 & -23 & 10 & 5.02 \\
\hline
\end{tabular}


Table 5. Identification of rCBF decreases in RECALL minus REST using strict criteria

\begin{tabular}{|c|c|c|c|c|c|c|c|c|c|}
\hline \multirow[b]{3}{*}{ Brain area } & \multicolumn{5}{|c|}{$\begin{array}{l}\text { Data from replication analysis } \\
\text { (data set divided as described in text) }\end{array}$} & & & & \\
\hline & \multicolumn{4}{|c|}{ Data set No. 1} & \multirow{2}{*}{$\begin{array}{l}\text { Data set } \\
\text { No. } 2 \\
\text { Significance }\end{array}$} & \multicolumn{4}{|c|}{$\begin{array}{l}\text { Best estimate of location and } t \text { value } \\
\text { (from combined data set) }\end{array}$} \\
\hline & $x$ & $y$ & $z$ & Magnitude & & $x$ & $y$ & $z$ & $t$ value \\
\hline Medial prefrontal & -1 & 57 & $\mathbf{0}$ & 90 & $p<0.05$ & -1 & 55 & -2 & 3.54 \\
\hline Medial prefrontal & 1 & 43 & 0 & 78 & $p=0.06$ & -3 & 37 & -6 & 5.11 \\
\hline Left parietal & -37 & -37 & 46 & 67 & $p<0.005$ & -37 & -39 & 48 & 4.96 \\
\hline Left extrastriate (BA 19) & -15 & -91 & 24 & 81 & $p<0.005$ & No $\mathrm{p}$ & & & \\
\hline Left extrastriate (BA 19) & -45 & -73 & 6 & 66 & $p<0.005$ & -41 & -79 & 2 & 6.89 \\
\hline Left prefrontal (BA 47) & -43 & 39 & -2 & 64 & $p<0.05$ & -41 & 39 & -2 & 3.64 \\
\hline Left parietal & -23 & -53 & 58 & 61 & $p<0.05$ & -21 & -51 & 58 & 4.85 \\
\hline Right parietal & 47 & -61 & 24 & 80 & $p<0.05$ & 45 & -61 & 22 & 5.67 \\
\hline Right inferior temporal & 49 & -33 & -16 & 67 & $p<0.05$ & 49 & -35 & -14 & 4.43 \\
\hline Right parietal & 29 & -39 & 46 & 60 & $p<0.05$ & 29 & -39 & 44 & 4.38 \\
\hline Right extrastriate (BA 19) & 35 & -77 & 30 & 57 & $p<0.05$ & No $p$ & & & \\
\hline Right extrastriate (BA 18) & 21 & -85 & -4 & 55 & $p<0.05$ & 27 & -87 & 6 & 5.49 \\
\hline Right extrastriate (BA 19) & 25 & -49 & -4 & 52 & $p<0.05$ & 23 & -49 & -2 & 4.69 \\
\hline Medial parietal & 17 & -55 & 22 & 50 & $p<0.01$ & 5 & -57 & 26 & 3.04 \\
\hline
\end{tabular}

See legend to Table 2.

Strick, in press), was activated in addition to a more posterior area, possibly SMA proper, already activated by REPETITION (compared with REST). The behavior of these two areas (anterior pre-SMA location $=-3,13,50$; posterior SMA proper location $=$ $-7,-1,56$ ) was tracked across multiple conditions (Fig. 4). What emerged was that pre-SMA became robustly activated during both PICTURE RECALL and AUDITORY WORD RECALL, compared with either reference task. REPETITION compared with REST showed only minimal activation in pre-SMA, suggesting that it was selectively activated during RECALL. The posterior area, however, was activated during both RECALL and REPETITION compared with REST, suggesting that it was commonly used across the two kinds of tasks-and is likely within SMA proper.

The idea that multiple divisions of human SMA can be distinguished by activation studies has been suggested previously (Picard and Strick, in press). One possibility is that internally generated motor programs are facilitated by the additional recruitment of pre-SMA. This would explain the observed dissociation between RECALL, which required outputting a word from memory, and REPETITION, which required saying aloud a word presented to the subjects.

To further explore this possibility, previous data collected during a word reading task (Buckner et al., 1995c) were examined. Word reading is similar to REPETITION, but verbal output is directed by a visual cue. Fixation was the control. This task subtraction was compared with another subtraction involving the commonly studied verb generation task, which relies on an internally driven response, much like RECALL (Raichle, 1994; Raichle et al., 1994). For verb generation, word reading was the reference task making the comparisons comparable to those in the present study. The data (Fig. 4) revealed activation of the same two divisions of medial frontal cortex. Anterior pre-SMA was activated in verb generation minus word reading $(-7,13,52 ; 31$ PET counts, using the PETT VI tomograph), and SMA proper was activated by word reading minus fixation $(-3,1,58 ; 56$ PET counts).

\section{Visual regions previously activated during picture viewing}

Table 10 shows the locations of the five regions identified in our previous picture-viewing study (Buckner et al., 1995c). Each of these regions was tracked across the task subtractions in the present experiment. Surprisingly, none of these regions showed rCBF increases during PICTURE RECALL.

In contrast, the visual regions showed marked decreases in rCBF across several of the task comparisons. The most robust decreases were present when either of the RECALL tasks were compared with REST. Such rCBF decreases were also detected in the previous replication analyses and were among the most reliable activations determined in this study. These findings, although not predicted in the context of memory retrieval, parallel a phenomenon observed by Haxby and colleagues (Haxby et al., 1994; Fiez et al., 1995). Haxby noted robust rCBF decreases in auditory and somatosensory cortex while subjects attended to visual stimuli. They argued that their observed decreases reflected a crossmodal suppression effect. A similar phenomenon may be revealing itself in relation to attention to auditory stimuli in the present study.

A post hoc examination of the REPETITION minus REST subtraction supports this idea because robust visual cortex rCBF decreases were again noted (Fig. 3). The REPETITION task also 

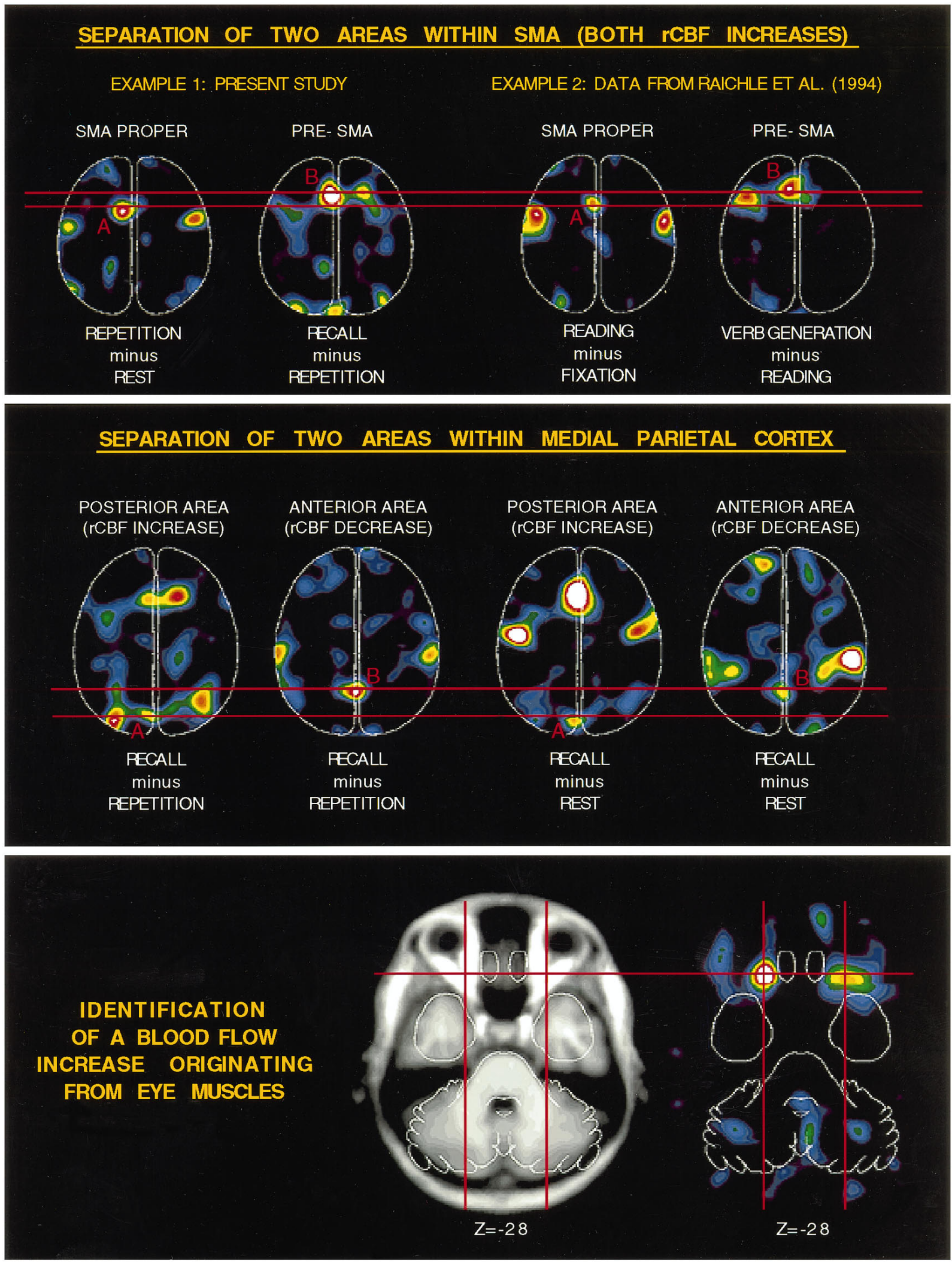

Figure 4. Horizontal sections show PET data as in Figure 3. Top, rCBF change for two distinct areas along medial frontal cortex are shown separately for two different sets of tasks. REPETITION minus REST reveals a posterior medial frontal activation in SMA (SMA PROPER). In addition to this activation, RECALL minus REPETITION reveals a second more anterior activation (PRE-SMA). The same separation between posterior and anterior divisions of medial frontal cortex is shown for READING minus FIXATION (SMA PROPER) and VERB GENERATION minus READING (PRE-SMA). Middle, Two separate medial parietal areas show rCBF change. A more posterior area shows an rCBF increase in RECALL compared with either REPETITION or REST, whereas a second more anterior area shows a reliable rCBF decrease in the same subtraction images. Bottom, A bilateral rCBF increase (right) is shown that appears to originate from somewhere within the eye muscles as demonstrated by comparison to an averaged MRI image (left). 
Table 6. Identification of rCBF increases in RECALL minus REPETITION using lenient criteria

\begin{tabular}{|c|c|c|c|c|c|}
\hline \multirow[b]{2}{*}{ Brain area } & \multicolumn{5}{|c|}{ Data from combined data set } \\
\hline & $x$ & $y$ & $z$ & Magnitude & $t$ value \\
\hline Posterior medial cerebellum & 9 & -73 & -20 & 62 & 3.57 \\
\hline BA 6 or cingulate & 17 & 17 & 42 & 58 & 4.48 \\
\hline Near BA 31 & 3 & -37 & 28 & 51 & 4.21 \\
\hline
\end{tabular}

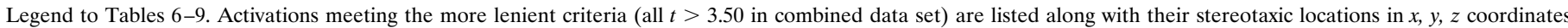
from the Talairach and Tournoux (1988) atlas.

\section{Table 7. Identification of rCBF increases in RECALL minus REST using lenient criteria}

\begin{tabular}{lccccc} 
& \multicolumn{2}{c}{ Data from combined data set } & & Magnitude & \\
\cline { 2 - 6 } Brain area & $x$ & $y$ & 8 & 76 & \\
\hline Medial thalamus & 5 & -11 & 0 & 57 & 4.94 \\
Left temporal (BA 21) & -49 & -49 & 05 & 7.05 \\
\hline
\end{tabular}

See legend to Table 6.

Table 8. Identification of rCBF decreases in RECALL minus REST using lenient criteria

\begin{tabular}{|c|c|c|c|c|c|}
\hline \multirow[b]{2}{*}{ Brain area } & \multicolumn{5}{|c|}{ Data from combined data set } \\
\hline & $x$ & $y$ & $z$ & Magnitude & $t$ value \\
\hline Left extrastriate (BA 18) & -23 & -93 & 14 & -76 & 6.86 \\
\hline
\end{tabular}

See legend to Table 6 .

Table 9. Identification of rCBF increases in PICTURE RECALL minus AUDITORY WORD RECALL using lenient criteria

\begin{tabular}{|c|c|c|c|c|c|}
\hline \multirow[b]{2}{*}{ Brain area } & \multicolumn{5}{|c|}{ Data from combined data set } \\
\hline & $x$ & $y$ & $z$ & Magnitude & $t$ value \\
\hline Left temporal (BA 21/37) & -57 & -41 & -6 & 52 & 3.58 \\
\hline Right lateral cerebellum & 41 & -75 & -22 & 57 & 4.42 \\
\hline Putamen & 27 & -7 & 0 & 56 & 5.69 \\
\hline
\end{tabular}

See legend to Table 6.

demanded the use of auditory information but did not require long-term episodic memory retrieval.

Moreover, rCBF decreases also were noted in somatosensory cortex for all of the tasks involving auditory stimulation compared with rest, suggesting that the effect is not specific to interactions between only visual and auditory cortices. This later finding is also consistent with the work of Haxby et al. (1994), who found such effects in somatosensory cortex during visual attention, and with Kawashima et al. (1994), who noted visual cortex reductions during somatosensory stimulation.

\section{Bilateral frontal-opercular cortex}

A surprising finding was that bilateral frontal-opercular areas were activated during the RECALL tasks compared with either of the references tasks. Such a finding suggests that these areas may play a role in episodic retrieval. However, these areas have not previously been reported as active during episodic retrieval tasks. To explore the possibility that such activations might have been missed during previous analyses, we reanalyzed data from our earlier set of experiments involving episodic retrieval using the stem-cued recall task (Buckner et al., 1995a). Stem-cued recall consists of having subjects retrieve previously studied words (e.g.,
"COURSE") using word stems as visual cues (e.g., "COU”). Three experiments were included in this earlier report and all had subjects do a variation of this stem-cued recall task. A low-level fixation control task was studied that is comparable, in many respects, to the REST control task of the present experiment. This subtraction (stem-cued recall minus fixation) was not analyzed in a formal manner in the original report of the data. However, bilateral frontal-opercular areas were visually present in one of the figures (Buckner et al., 1995a, their Fig. 2).

Reanalysis of stem-cued recall minus fixation using a formal procedure revealed that bilateral frontal-opercular activations were reliably present in that data set, but only at a relatively weak level (left $=-25,21,14$, mean $=42$ PET counts, $n=32, t=5.24$; right $=27,27,6$, mean $=22$ PET counts, $n=32, t=3.76$; both $p<0.0005$ uncorrected). In each dimension, these two peaks are within $10 \mathrm{~mm}$ of the peak $\mathrm{rCBF}$ increases detected in the RECALL minus REST comparison image. Moreover, an independent activation peak on the left side was localized more laterally $(-41,17,14$, mean $=40$ PET counts, $n=32, t=5.12, p<0.0001$ uncorrected). This second peak more closely localized to a left inferior prefrontal area that has been commonly activated during 
REGIONAL BEHAVIORAL OF TWO MEDIAL PARIETAL LOCATIONS

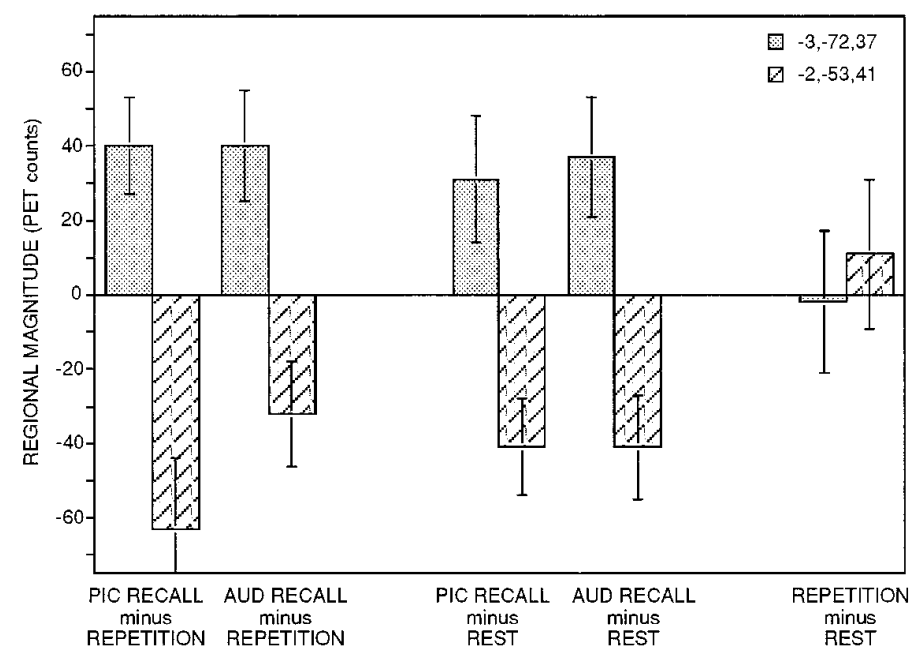

REGIONAL BEHAVIORAL OF TWO SMA LOCATIONS

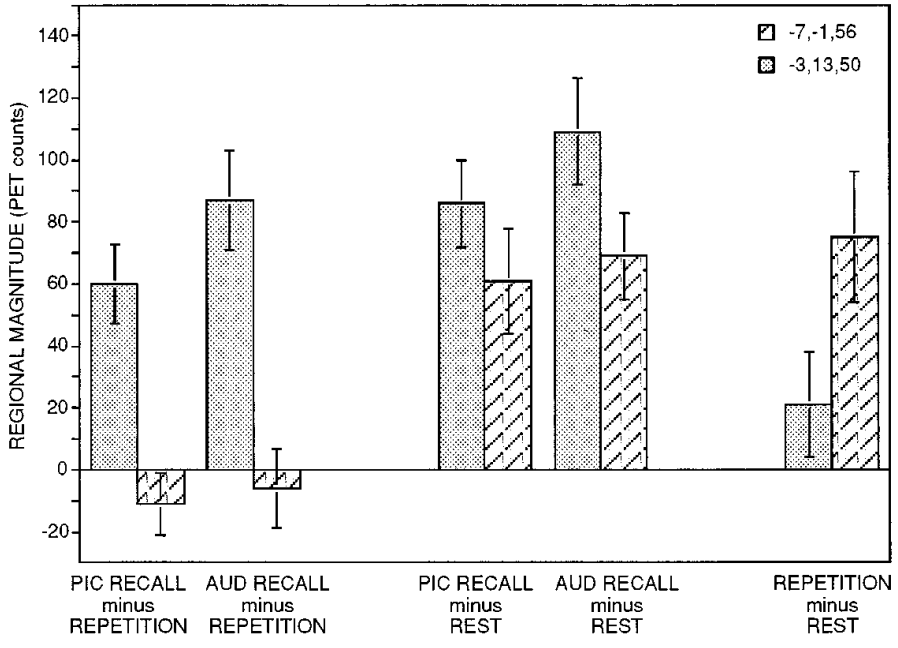

Figure 5. Regional activation magnitudes are displayed with SE bars. Each region was tracked across multiple subtraction pairs as listed on the $x$-axis. Left panel, Regional rCBF change for two separate parietal regions. The two regions, which show completely opposite behavior, change rCBF in relation to the RECALL task compared with either of the reference tasks, whereas both show no rCBF change when the two reference tasks are compared directly. Right panel, Regional rCBF change for two separate divisions of medial frontal cortex. One area (SMA proper), shown with lighter shading, increased rCBF for both RECALL and REPETITION compared with REST, whereas the second area (pre-SMA) showed an rCBF increase only during RECALL.

\begin{tabular}{|c|c|c|c|c|c|c|c|c|c|c|c|c|}
\hline \multicolumn{2}{|c|}{ Location } & \multirow[b]{2}{*}{$z$} & \multicolumn{2}{|c|}{$\begin{array}{l}\text { PICTURE RECALL } \\
\text { minus } \\
\text { AUD. WORD } \\
\text { RECALL }\end{array}$} & \multicolumn{2}{|c|}{$\begin{array}{l}\text { PICTURE } \\
\text { RECALL } \\
\text { minus } \\
\text { REPETITION }\end{array}$} & \multicolumn{2}{|c|}{$\begin{array}{l}\text { PICTURE } \\
\text { RECALL } \\
\text { minus } \\
\text { REST } \\
\end{array}$} & \multicolumn{2}{|c|}{$\begin{array}{l}\text { AUD. WORD } \\
\text { RECALL } \\
\text { minus } \\
\text { REPETITION }\end{array}$} & \multicolumn{2}{|c|}{$\begin{array}{l}\text { AUD. WORD } \\
\text { RECALL } \\
\text { minus } \\
\text { REST } \\
\end{array}$} \\
\hline$x$ & $y$ & & Mean & SE & Mean & SE & Mean & SE & Mean & SE & Mean & SE \\
\hline-21 & -91 & 18 & -4 & 10 & -16 & 11 & -77 & 15 & -1 & 11 & -73 & 15 \\
\hline 33 & -57 & -2 & -1 & 15 & -25 & 13 & -35 & 18 & -37 & 17 & -41 & 11 \\
\hline 41 & -79 & 4 & -11 & 12 & -25 & 9 & -68 & 14 & -14 & 13 & -58 & 14 \\
\hline
\end{tabular}

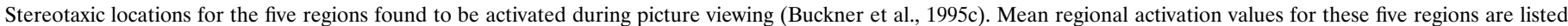

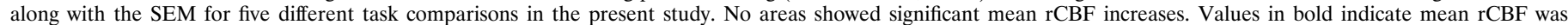
significantly decreased below zero $(p<0.05)$.

certain kinds of word access tasks whether or not they contain episodic retrieval demands (Buckner and Petersen, 1996). It seems quite possible that there exists one left inferior/frontalopercular area that is activated by stem-cued recall and many other word access tasks, and a second more medial area, activated bilaterally, that is common to the episodic retrieval tasks. However, this observation will have to await further exploration to be determined with confidence.

\section{Results of within-subject analysis}

Of 11 subjects who had a sufficient data set for within-subject analyses, six demonstrated right anterior prefrontal activations and six demonstrated medial parietal activations that met identification criteria. Data from several of these subjects are presented in Figure 6. The presented data come from those subjects whose activations made the largest contributions to the group averaged image using a "weighted mean," i.e., weighting distance from the averaged location and peak magnitude of the activation. In this way, the data displayed represent activations passing a conservative magnitude threshold and also represent those subjects who contributed most to the replicated group activations.
For the right anterior prefrontal activation, subjects P2503, P2518, and P2526 were the most certain activations with weighted magnitudes of 86,83 , and 73 PET counts, respectively; for the medial parietal activation, subjects P2539, P2526, and P2525 were with weighted means of 75, 61, and 55 PET counts, respectively.

Based on Damasio (1995), the right anterior prefrontal activation localized at or near the depth of the superior frontal sulcus. In the Talairach and Tournoux atlas (1988), this area corresponds to the border between Brodmann area (BA) 10 and 46. Recent analysis of anatomical variability by Rajkowska and Goldman-Rakic (1995) suggests it is possible that these activations may even fall in BA 9. In addition, many of the individual subjects showed a noticeable left anterior prefrontal activation. This left prefrontal activation was not replicated in the group-averaged analysis, although it is visually present (see Fig. 3). In some of the individual subjects, this left anterior prefrontal activation was of greater magnitude than the right anterior activation (e.g., P2503).

The medial parietal activations (rCBF increases) localized remarkably well to the parieto-occipital sulcus (POS), which borders precuneus and cuneus. Identification of the POS was accom- 


\section{RIGHT ANTERIOR PREFRONTAL}
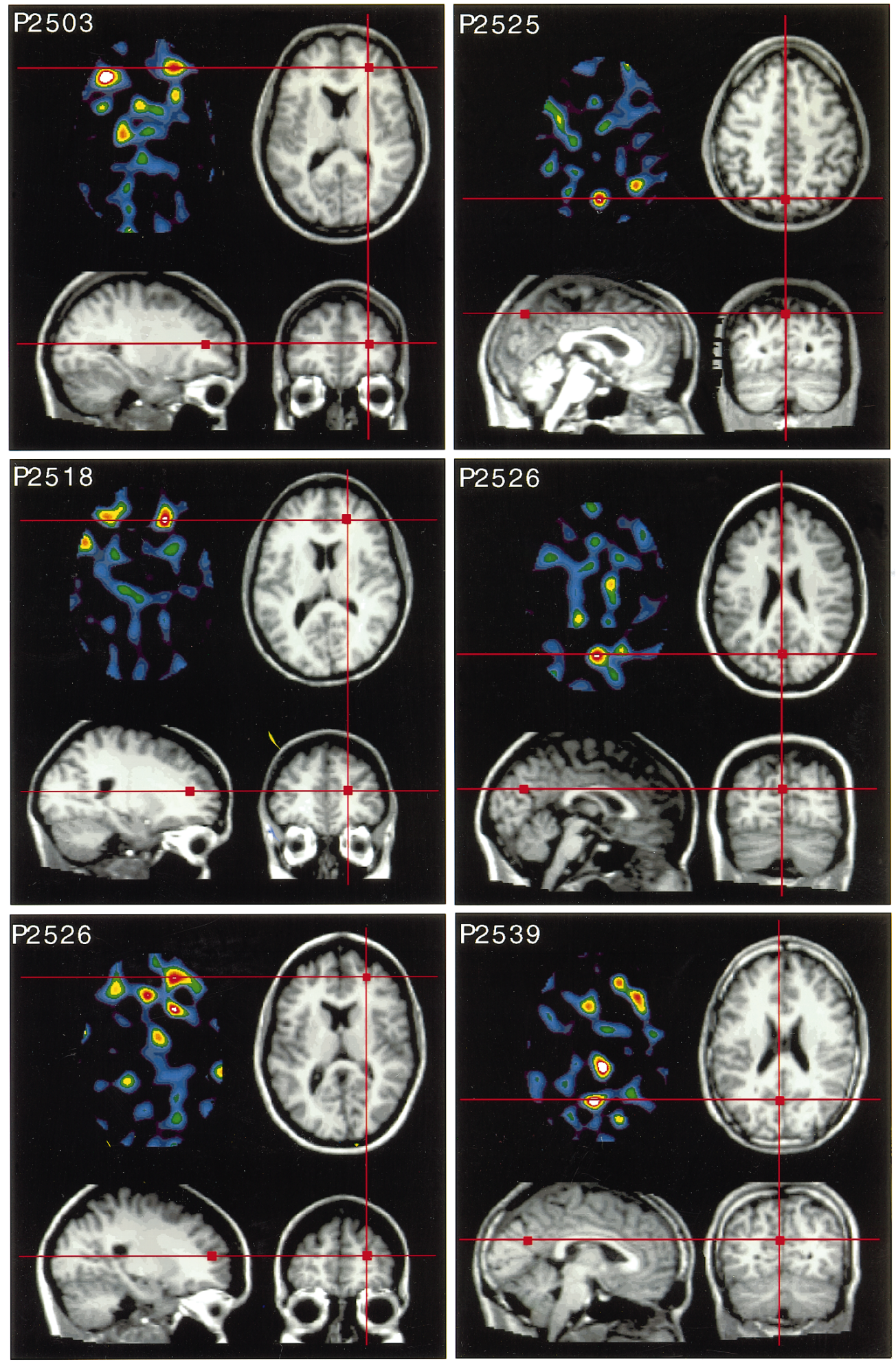

\section{POSTERIOR MEDIAL PARIETAL}
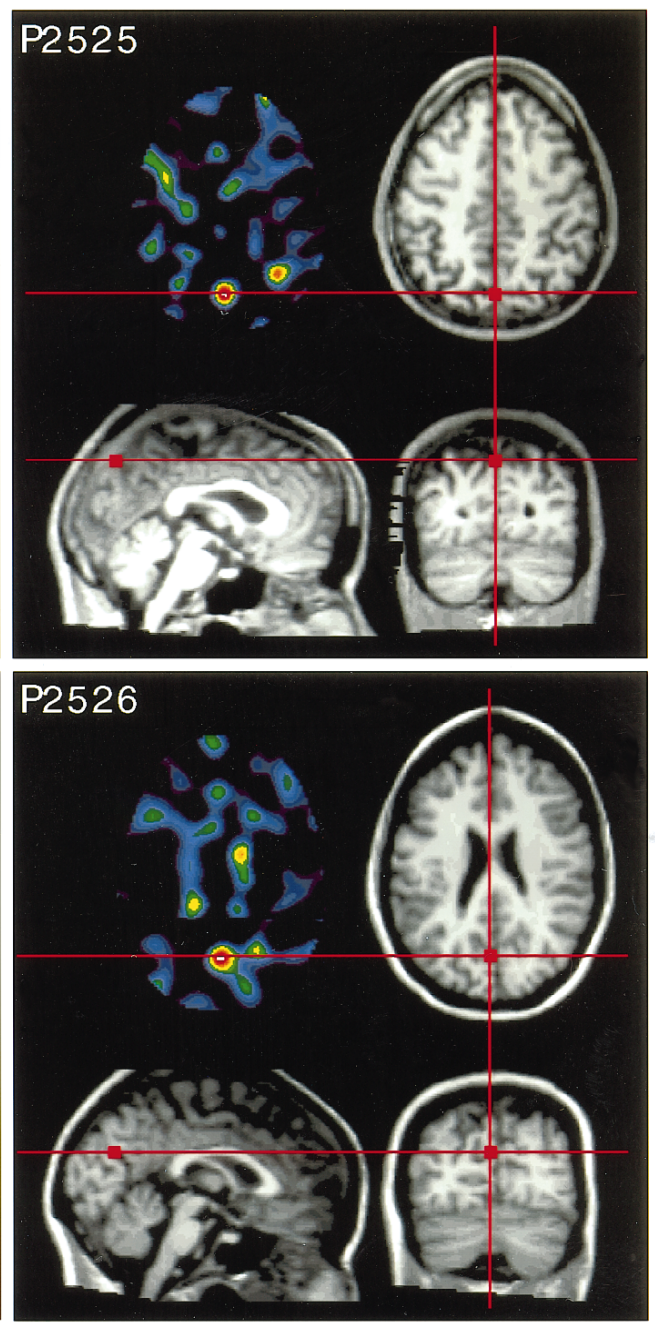

Figure 6. Within-subject PET activation data are shown coregistered with structural MRI data. Three single subject activations for each of two areas are shown (see Results). The color sections are transverse PET images with raw subtracted PET data from each subject. Images are scaled near the slice maximum. Three separate MRI views of each subject are aligned to center on the peak activation identified in the PET image (see Materials and Methods). Red lines and square markings show corresponding locations across the different modality types and views. plished by marking multiple-point locations in a sagittal view and projecting these points onto the transverse sections similar to Damasio (1995). The location of activation along the POS varied across subjects. In P2525, for example, the activation plotted near the most dorsal extent of the POS. For subjects P2526 and P2539, the activation fell about halfway between the dorsal-most extent of the POS and its intersection with the calcarine sulcus. Based on
Talairach and Tournoux (1988), these activations most likely fall within posterior BA 7, or possibly BA 19.

These localizations should be interpreted conservatively because of the several sources of error (e.g., error induced by PET-MR coregistration, resolution of the 953B tomograph, and volume averaging errors that might bias peak activation location estimates toward denser gray matter regions). 


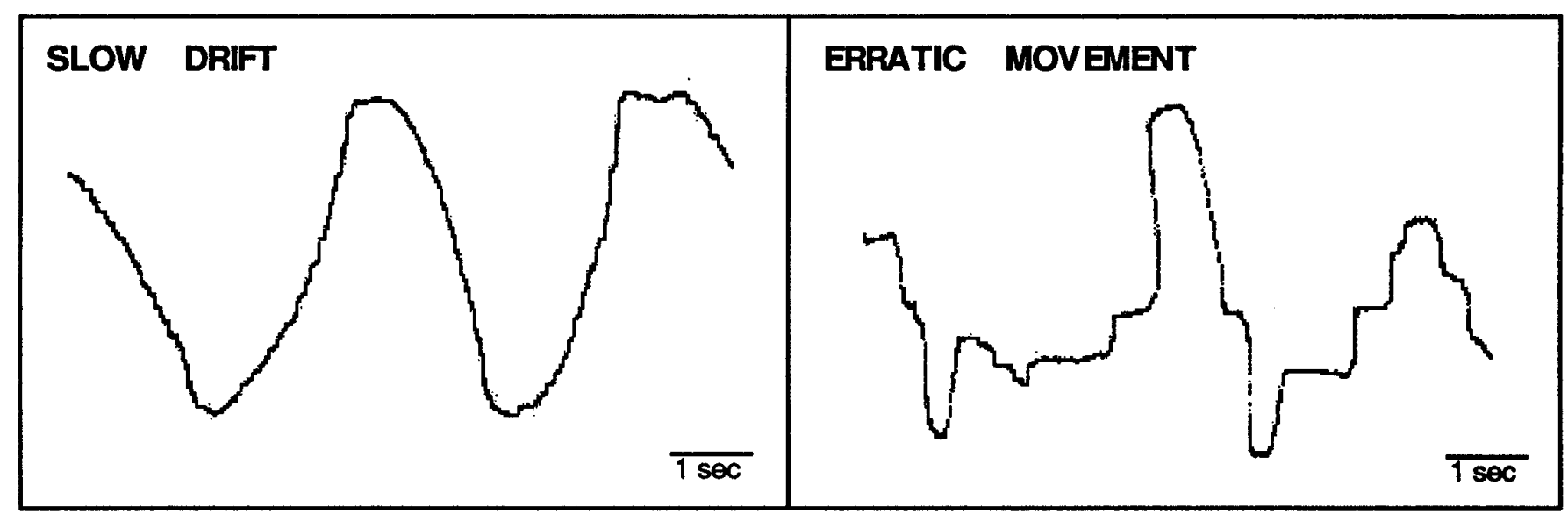

Figure 7. Examples of slow drift and erratic movement as measured by the horizontal EOG for subject p2537. Vertical displacement on the record reflects horizontal eye movements. Time bar indicates scale of horizontal axis.

\section{EOG results}

Each horizontal eye movement record was quantified to detect individual saccades (square-wave jerks), slow drifting eye movements (Fig. 7), and erratic movements (Fig. 7). There were few isolated square-wave jerk saccades $(\leq 3$ per scan condition, on average) during any of the task conditions. Considerable portions of the records, however, contained periods of erratic eye movements. These erratic eye movements are most likely the product of random frequent saccades that could not be individually isolated given our recording methods and are consistent with the experimental procedure that required subjects to close their eyes during the task conditions.

Erratic eye movements were quantified in terms of the percentage of the task period that contained erratic movements. Erratic eye movements decreased as a function of the complexity of the scan task: $66 \%$ for RECALL, $43 \%$ for REPEAT, and $28 \%$ for REST. The difference between RECALL and REST was significant $(t[13]=3.36 ; p<0.01)$, and the difference between RECALL and REPEAT showed a trend $(t[13]=1.78 ; p=0.09)$. PICTURE RECALL and AUDITORY WORD RECALL were nearly identical (68 and 64\%, respectively).

Slow drifting eye movements, which did not involve saccades, showed the exact opposite pattern: $2 \%$ for RECALL, $13 \%$ for REPEAT, and $42 \%$ for REST. The difference between RECALL and REST was significant $(t[13]=3.85 ; p<0.01)$ as was the difference between REPEAT and REST $(t[13]=3.24 ; p<0.01)$. The difference between RECALL and REPEAT showed only a trend for significance $(t[13]=1.88 ; p=0.08)$.

The presence of substantial periods of slow drifting eye movements during REST may suggest that the REST condition involved a lesser level of arousal than any of the other more active task conditions.

\section{Identification of a potential eye muscle artifact}

After initial inspection of the data from the RECALL minus REST and RECALL minus REPEAT subtraction images, there appeared to be a bilateral activation in inferior orbital frontal cortex. However, when the images were viewed without a template masking the brain, the orbital frontal activations were found to originate from a source inferior to the brain. Coregistration with MRI suggested that the activation sources localized to the region of the eye muscles (Fig. 4). This finding is consistent with the observation that RECALL elicited more erratic eye move- ments than either REST or REPEAT. Thus, it seems that a blood flow response in the region of the eye muscles can be modulated by task demands and/or behavioral output. Moreover, this response can produce an artifact that appears within the brainespecially when viewed in a templated image in which activity outside the brain is not visualized (Drevets et al., 1992).

\section{DISCUSSION}

Two episodic memory retrieval tasks involving paired-associate recall were studied. One task relied on pictorial retrieval (PICTURE RECALL) and the second relied on auditory word retrieval (AUDITORY WORD RECALL). When the direct comparison between PICTURE RECALL and AUDITORY WORD RECALL was analyzed, few noteworthy activation differences were detected between the two tasks. Many robust and reliable activations were, however, detected across the two tasks. For this reason, the two tasks will be discussed collectively as RECALL. The commonalities will be discussed first.

During the RECALL tasks, a distributed pathway of brain areas was activated. This pathway included areas in auditory cortex, bilateral frontal-opercular cortex, anterior cingulate, posterior medial parietal cortex, right anterior prefrontal cortex, two separable areas of medial frontal cortex (SMA proper and pre-SMA), motor cortex, and cerebellar areas. Components of this pathway, as they relate to other episodic retrieval tasks and nonepisodic retrieval tasks, can only be appreciated by comparing data from multiple studies.

To facilitate such a comparison, Figure 8 presents heuristic diagrams of tentative cortical pathways activated during four different tasks involving memory retrieval: (1) the paired-associate RECALL tasks discussed in this paper; (2) another set of episodic retrieval tasks based on stem-cued recall (Buckner et al., 1995a,b); (3) the well studied verb generation task, which has semantic memory retrieval demands (Petersen et al., 1988, 1989; Raichle et al., 1994; Buckner et al., 1995b); and (4) stem completion, a second task that has semantic retrieval demands (Buckner et al., 1995a). These tasks are useful to compare because they all required subjects to perceive cues and say aloud words intentionally retrieved from memory, but only two of the tasks relied on episodic memory (RECALL and stem-cued recall).

Contrasting these tasks reveals a common set of areas that appears to underlie processes generally related to accessing and producing words. The common areas include left inferior prefron- 
PAIRED-ASSOCIATE RECALL (EPISODIC MEMORY TASK)

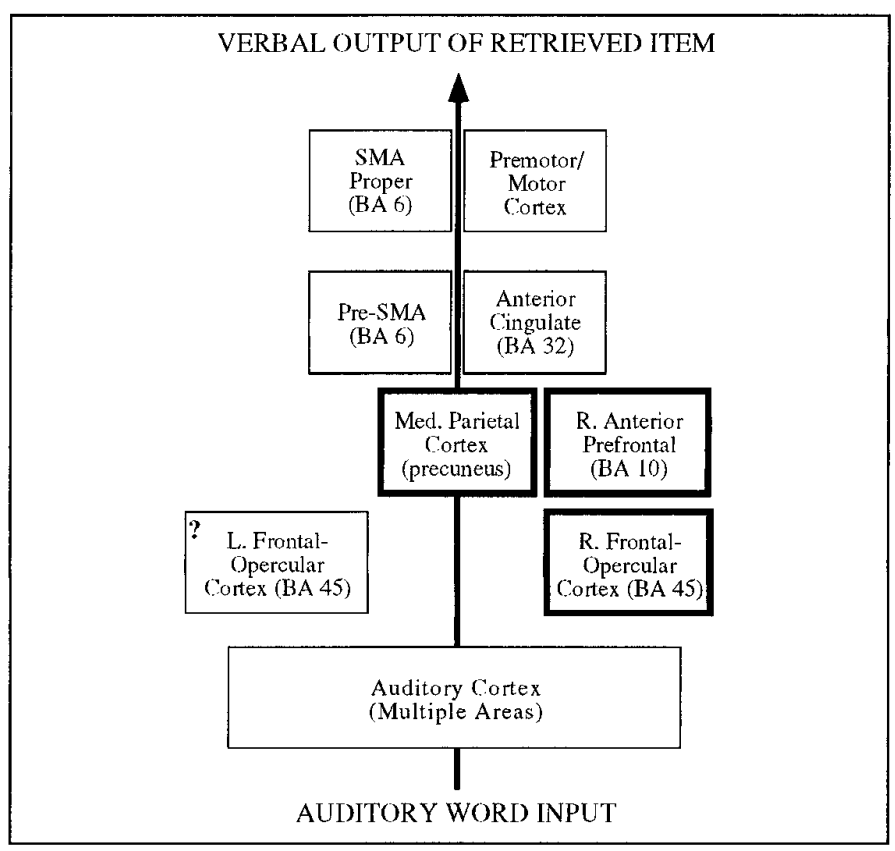

VERB GENERATION (SEMANTIC MEMORY TASK)

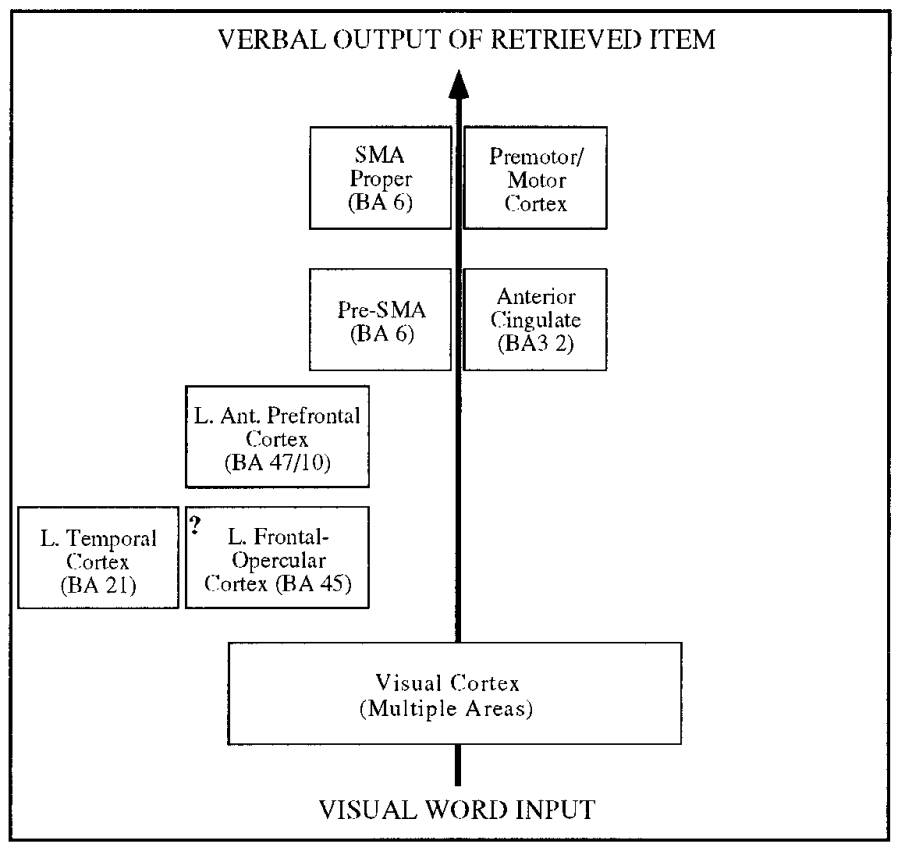

STEM-CUED RECALL (EPISODIC MEMORY TASK)

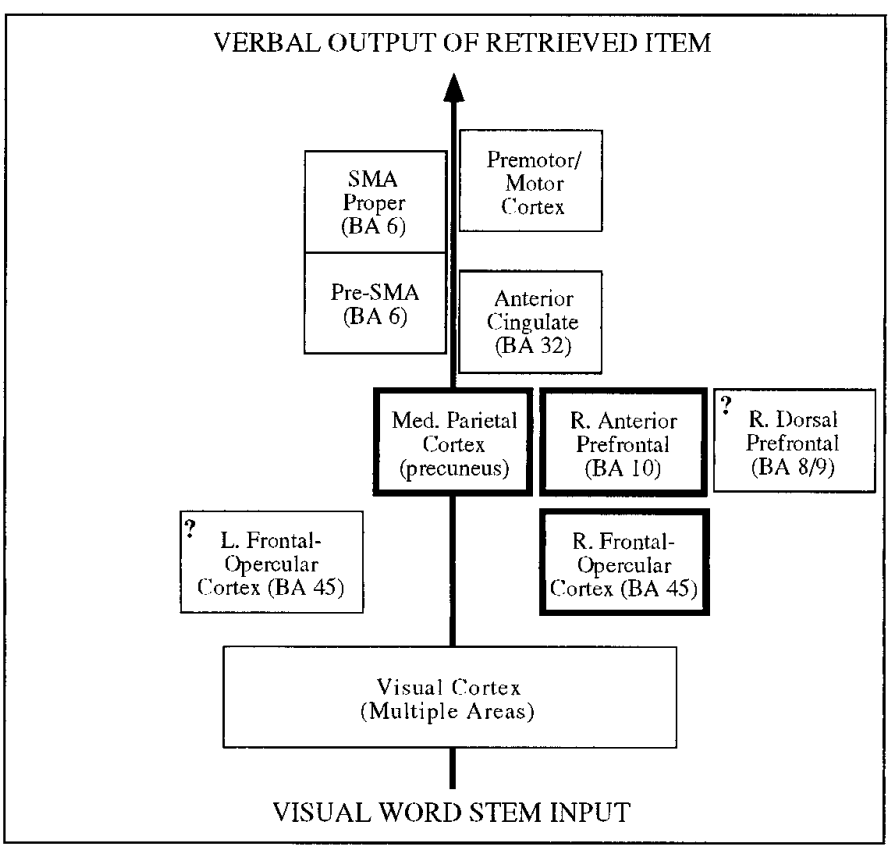

STEM-COMPLETION (SEMANTIC MEMORY TASK)

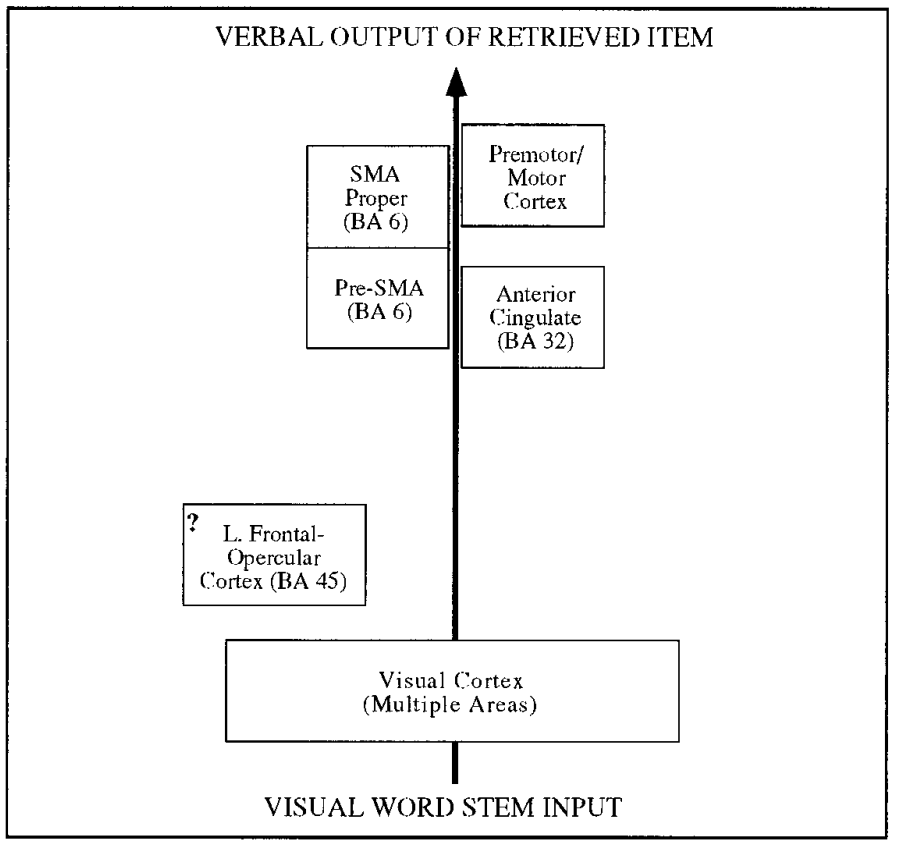

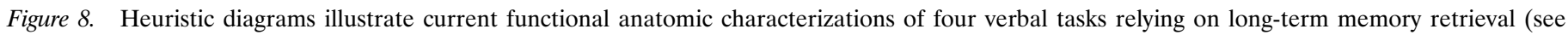

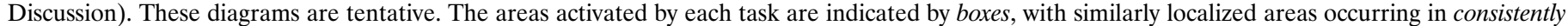

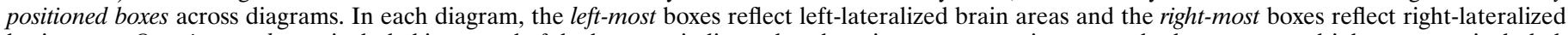

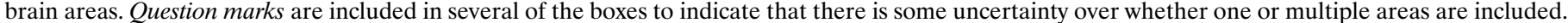

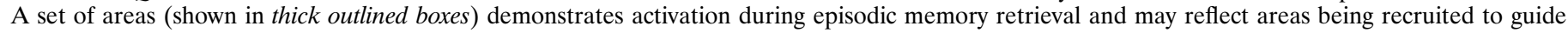

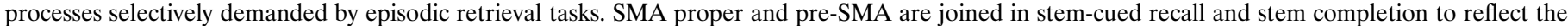

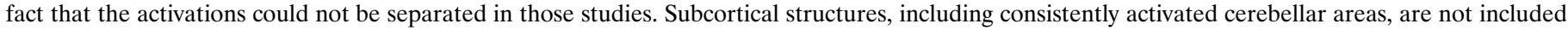
in these diagrams for simplicity.

tal cortex in or near frontal-opercular cortex, anterior cingulate, and pre-SMA. Also shared in common were SMA proper and motor cortex, which probably play a relatively direct role in programming the motor aspect of speech (Petersen and Fiez,
1993). The finding that the detected functional anatomy of the episodic retrieval tasks overlaps considerably with the other memory retrieval/speech production tasks suggests that verbal episodic retrieval may be considered as a specialized form of these tasks 
with additional areas being activated to support processes more specific to the episodic memory tasks. Most interesting to the understanding of episodic memory retrieval are the right anterior prefrontal, posterior medial parietal, and bilateral frontalopercular areas, which were activated by the episodic tasks but not by the others. Each of these additional areas will be discussed.

Right anterior prefrontal activation, at or near BA 10, has now been observed across several tasks involving episodic retrieval (for review, see Buckner and Petersen). The observation of activation in the present RECALL tasks establishes that such activation is not attributable to the alternation between task strategies, as was possible given earlier experimental confounds (Buckner et al., 1995a; Swick and Knight, 1996). Our methods and registration to MRI also expand our knowledge by beginning an accumulation of within-subject imaging data, which suggest that this area falls within the superior frontal sulcus. Such data, when combined with the detailed human anatomic (Petrides and Pandya, 1994; Rajkowska and Goldman-Rakic, 1995a,b) and lesion-behavior (Swick and Knight, 1996) analyses that are emerging, will likely provide a more detailed understanding of the specific contributions of these frontal regions.

As for the specific role this right anterior prefrontal area contributes to episodic memory, some have suggested that processes related to retrieval effort and search are the most likely candidates (Schacter et al., 1996). Although this possibility seems reasonable, it is a bit early to be certain. In Buckner et al. (1995b) and in the present data, activation of right anterior prefrontal cortex is markedly diminished depending on the reference task. It seems possible that the REST state allows for more diffuse cognitive processing, which may overlap with processes directly demanded by the episodic retrieval tasks (Andreasen et al., 1995b). Consistent with this possibility, the EOG data showed indications of a different level of arousal during the REST condition. However, this possibility does not account for the many stable activations that remain during comparisons to such reference tasks (e.g., posterior medial parietal cortex). Furthermore, one recent report of activation within this area suggests that the domain of its involvement may extend beyond episodic memory (MacLeod et al., 1995). Taken together, the present data suggest that right anterior prefrontal cortex plays a fairly selective role in episodic retrieval, but the details of its involvement, and its possible involvement in other tasks, will need to be explored further.

The second area emerging as a candidate for a prominent role in episodic retrieval is the posterior medial parietal cortex (near precuneus). Although we have observed this activation previously, its potential contribution to episodic memory was not appreciated because large, closely localized rCBF decreases were observed in another comparison not involving episodic retrieval (Buckner et al., 1995a). The present data suggest that there are multiple, functionally dissociable areas in medial parietal cortex: a posterior area that often shows increased $\mathrm{rCBF}$ during episodic retrieval (present study: -3, -72, 37; Andreasen et al., 1995a: -1, -71, 41 and $-2,-69,39$; Buckner et al., 1995a: $-3,-63$, 43; Fletcher et al., 1995a: $-6,-68,36$ and 12, -72, 28; Petrides et al., 1995: -5, $-73,49$ and 3, -76, 44; Schacter et al., 1996: 5, -72, 32) and a more anterior area that shows $\mathrm{rCBF}$ change on a yet undetermined dimension (present study: $-2,-53,41$; Buckner et al., 1995a: 5, -48, 39 and -3, -54, 43; Grabowski et al., 1996: 2, -56, 30; Haxby et al., 1994: 6, $-50,44$ and $-14,-50,48$ ) (see also Shulman et al., 1996).

Fletcher et al. (1995a) were among the first to propose that posterior medial parietal cortex (at or near precuneus) might play a role in episodic retrieval. The present data are consistent with this general notion and provide an explanation for contradictory data by demonstrating the existence of two functionally distinct areas. It seems that many reported medial parietal deactivations (which appeared unrelated to episodic retrieval) are spatially distinct from the area being activated by episodic retrieval. In addition, by examining within-subject data, the location of this activation was tentatively localized to the parieto-occipital sulcus.

One hypothesis about the role this area plays in episodic retrieval is that it participates in imagery processes inherent to episodic retrieval (Fletcher et al., 1995a,b). The present study does not support this hypothesis because potential imagery contributions were systematically manipulated, and posterior medial parietal rCBF was not changed (Fig. 5). Furthermore, episodic retrieval tasks involving faces, which rely extensively on nonverbal forms of memory, have not reported activation within this area (Grady et al., 1995; Haxby et al., 1996). Imagery-related modulations were noted in one study, but the location of the activations fell in the anterior medial parietal area discussed earlier and not in the more posterior area consistently activated during episodic retrieval (Fletcher et al., 1995b, their Fig. 1) (mean $y$ coordinate $=$ -53 , all anterior to $y=-58)$. Moreover, Schacter et al. (1996) reported posterior medial parietal activation during a difficult recall condition in which subjects were failing to recall information on most trials compared with an easy recall condition. Such data suggest that the activation is related to retrieval effort or retrieval mode, which may or may not overlap with an imagery hypothesis.

Robust activations were observed in bilateral frontal-opercular cortex during RECALL. Although such activations have not previously been reported during episodic retrieval, a reanalysis of an older set of stem-cued recall tasks suggested that these areas may be activated more often then originally thought. The consistency of this bilateral activation across five episodic retrieval tasks [three tasks in Buckner et al. (1995a) and the present two tasks] suggests that frontal-opercular areas may play a role in episodic retrieval. There have been other tasks outside the domain of episodic retrieval that have activated similar areas (Fiez et al., 1995). Thus, it is not yet clear what the common processing components of these tasks are. Tentatively, in the context of episodic memory tasks, we would suggest that the processing component activating these areas might be related to retrieval match.

The most perplexing finding was the absence of large differences between PICTURE RECALL and AUDITORY WORD RECALL, especially in visual cortex. This is because PICTURE RECALL was designed to have an imagery component, and much recent data have supported the notion that visual extrastriate cortex and possibly earlier visual areas participate in such processes (Kosslyn et al., 1993; Kosslyn and Ochsner, 1994). The data set in which the two tasks were directly compared was fairly large, with 22 separate subtraction pairs from 14 subjects. One possibility is that PICTURE RECALL lacked sufficient task demands to truly require retrieval based on imagery. Given the absence of notable activations, this possibility should be taken seriously and will need to be explored in future studies that place more direct demands on visual imagery and recall processes.

An activation was noted in left temporal cortex (see Table 9). Although this activation was not replicated by the strict analysis criteria, it is worthwhile to note that this activation falls within the vicinity of a region proposed to play a role in imagery demands based on neuropsychological findings (Farah, 1995).

Comparisons of RECALL to REPETITION or REST also did 
not reveal any activations in visual cortex. Rather, the comparison to REST revealed robust $\mathrm{rCBF}$ decreases in several visual areas, which may reflect a form of crossmodal suppression (Haxby et al., 1994). Thus, a possible, although post hoc, explanation for the lack of visual rCBF increases is that one or both of the RECALL tasks used areas in visual cortex but comparisons were overwhelmed by the suppression effects (Fig. 3). The alternative, that visual cortex simply was not activated by these RECALL tasks, presents an argument against the generality of several imagery models (Kosslyn, 1988; Kosslyn and Ochsner, 1994; Moscovitch et al., 1994) but cannot be strongly asserted based on this single result (but see also Fletcher et al., 1995b; Roland and Gulyás, 1995).

In summary, detailed functional anatomic descriptions of two episodic retrieval tasks were presented. At present, it appears that a family of tasks activate a closely related set of brain areas. This common pathway may be used to access and maintain representations of words during their retrieval and production-a set of demands common to many kinds of tasks, including, but extending beyond, episodic memory retrieval tasks. In addition to this common pathway, episodic memory retrieval tasks, which require access to information learned during a unique event, appear to activate right anterior prefrontal, posterior medial parietal, and possibly bilateral frontal-opercular cortex. The current results, in combination with converging data from other studies in the literature, provide a more complete characterization of pathways activated during episodic retrieval, a characterization to be continually updated with emerging information.

The present data additionally offer insight into more detailed aspects of the pathways activated during such tasks. Human SMA is often discussed as one area. Our data provide evidence within a single set of studies for a distinction between two subdivisions of medial frontal cortex (SMA proper and pre-SMA), as suggested by Picard and Strick (in press). Two subdivisions of medial parietal cortex were also demonstrated with only one of the areas (near precuneus) showing increased $\mathrm{rCBF}$ during episodic retrieval.

\section{REFERENCES}

Andreasen NC, O'Leary DS, Arndt S, Cizadlo T, Hurtig R, Rezai K, Watkins GL, Boles L, Ponto B, Hichwa R (1995a) Short-term and long-term verbal memory: a positron emission tomography study. Proc Natl Acad Sci USA 92:5111-5115.

Andreasen NC, O'Leary DS, Cizadlo T, Arndt S, Rezai K, Watkins GL, Boles Ponto LL, Hichwa RD (1995b) Remembering the past: two facets of episodic memory explored with positron emission tomography. Am J Psychiatry 152:1576-1585.

Buckner RL (1996) Beyond HERA: contributions of specific prefrontal brain areas to long-term memory retrieval. Psych Bull Rev 3:149-158.

Buckner RL, Petersen SE (1996) What has neuroimaging told us about prefrontal cortex involvement in long-term memory retrieval? Semin Neurosci 8:47-55.

Buckner RL, Petersen SE, Ojemann JG, Miezin FM, Squire LR, Raichle ME (1995a) Functional anatomical studies of explicit and implicit memory retrieval tasks. J Neurosci 15:12-29.

Buckner RL, Petersen SE, Raichle ME (1995b) Activation of human prefrontal cortex across different speech production tasks and gender groups. J Neurophysiol 74:2163-2173.

Buckner RL, Petersen SE, Miezin FM, Raichle ME, Corbetta M, Shulman GL (1995c) A right-extrastriate area that is selectively activated by pictures, faces, and tasks that require attention to form. Hum Brain Mapp (Suppl) 1:54.

Buckner RL, Corbetta M, Schatz J, Raichle ME, Petersen SE (1996) Preserved speech abilities and compensation following prefrontal damage. Proc Natl Acad Sci USA 93:1249-1253.

Corbetta M, Miezin FM, Shulman GL, Petersen SE (1993) A PET study of visuospatial attention. J Neurosci 13:1202-1226.
Damasio H (1995) Human brain anatomy in computerized images. New York: Oxford UP.

Drevets WC, Videen TO, MacLeod AK, Haller JW, Raichle ME (1992) PET images of blood flow changes during anxiety: correction. Science 256:1696.

Farah MJ (1995) Current issues in the neuropsychology of image generation. Neuropsychologia 33:1455-1471.

Fiez JA, Tallal P, Raichle ME, Miezin FM, Katz WF, Dobmeyer S, Petersen SE (1995) PET studies of auditory and phonological processing: effects of stimulus type and task condition. J Cognit Neurosci 7:357-375.

Fletcher PC, Frith CD, Grasby PM, Shallice T, Frackowiak RSJ, Dolan RJ (1995a) Brain systems for encoding and retrieval of auditory-verbal memory. Brain 118:401-416.

Fletcher PC, Frith CD, Baker SC, Shallice T, Frackowiak RSJ, Dolan RJ (1995b) The mind's eye-precuneus activation in memory related imagery. NeuroReport 2:195-200.

Fox PT, Mintun MA (1989) Noninvasive functional brain mapping by change-distribution analysis of averaged PET images of $\mathrm{H}_{2}{ }^{15} \mathrm{O}$. J Nucl Med 30:141-149.

Fox PT, Raichle ME (1986) Focal physiological uncoupling of cerebral blood flow and oxidative metabolism during somatosensory stimulation in human subjects. Proc Natl Acad Sci USA 83:1140-1144.

Fox PT, Mintun MA, Raichle ME, Herscovitch P (1984) A noninvasive approach to quantitative functional brain mapping with $\mathrm{H}_{2}{ }^{15} \mathrm{O}$ and positron emission tomography. J Cereb Blood Flow Metab 4:329-333.

Fox PT, Perlmutter JS, Raichle ME (1985) A stereotactic method of anatomical localization for positron emission tomography. J Comput Assist Tomogr 9:141-153.

Fox PT, Miezin FM, Allman JM, Van Essen DC, Raichle ME (1987) Retinotopic organization of human visual cortex mapped with positron emission tomography. J Neurosci 7:913-922.

Fox PT, Mintun MA, Reiman EM, Raichle ME (1988) Enhanced detection of focal brain responses using intersubject averaging and changedistribution analysis of subtracted PET images. J Cereb Blood Flow Metab 8:642-653.

Friston KJ, Frith CD, Liddle PF, Frackowiak RSJ (1991) Comparing functional (PET) images. The assessment of significant change. J Cereb Blood Flow Metab 11:690-699.

Frackowiak RSJ, Friston KJ (1995) Methodology of activation paradigms. In: Handbook of neuropsychology, Vol 10 (Boller F, Grafman J, eds), pp 369-382. Amsterdam: Elsevier.

Grabowski TJ, Frank RJ, Brown CK, Damasio H, Boles Ponto LL, Watkins GL, Hichwa RD 1996 Reliability of PET activation across statistical methods, subject groups, and sample sizes. Hum Brain Mapp 4:23-46.

Grady CL, McIntosh AR, Horwitz B, Maisog JM, Ungerleider LG, Mentis MJ, Pietrini P, Schapiro MB, Haxby JV (1995) Age-related reductions in human recognition memory due to impaired encoding. Science 269:218-221.

Haxby JV, Horwitz B, Ungerleider LG, Maisog JM, Pietrini P, Grady CL (1994) The functional organization of human extrastriate cortex: a PET-rCBF study of selective attention to faces and locations. J Neurosci 14:6336-6353.

Haxby JV, Horwitz B, Maisog JM, Ungerleider LG, Mishkin M, Schapiro MB, Rapoport SI, Grady CL (1996) Frontal and temporal participation in long-term recognition memory for faces: a PET-rCBF activation study. Proc Natl Acad Sci USA 93:922-927.

Herscovitch P, Markham J, Raichle ME (1983) Brain blood flow measured with intravenous $\mathrm{H}_{2}{ }^{15} \mathrm{O}$. I. Theory and error analysis. J Nucl Med 24:782-789.

Hunton DL, Miezin FM, Buckner RL, Raichle ME, Petersen SE (1996) An assessment of replication and functional-anatomical variability in functional neuroimaging studies. Hum Brain Mapp, in press.

Kapur S, Craik FIM, Tulving E, Wilson AA, Houle S, Brown GM (1994) Neuroanatomical correlates of encoding in episodic memory: levels of processing effect. Proc Natl Acad Sci USA 91:2008-2011.

Kawashima R, Roland PE, O'Sullivan BT (1994) Fields in human motor areas involved in preparation for reaching, actual reaching, and visualmotor learning: a positron emission tomography study. J Neurosci 14:3462-3474.

Klein D, Milner B, Zatorre RJ, Meyer E, Evans AC (1995) The neural substrates underlying word generation: a bilingual functional-imaging study. Proc Natl Acad Sci USA 92:2899-2903. 
Kosslyn SM (1988) Aspects of a cognitive neuroscience of mental imagery. Science 240:1621-1626.

Kosslyn SM, Ochsner KN (1994) In search of occipital activation during visual mental imagery. Trends Neurosci 17:290-292.

Kosslyn SM, Alpert NM, Thompson WL, Maljkovic V, Weise SB, Chabris CF, Hamilton SE, Rauch SL, Buonanno FS (1993) J Cognit Neurosci 5:263-287.

Kučera H, Francis W (1967) Computational analysis of present-day American English. Providence, RI: Brown UP.

MacLeod AK, Buckner RL, Petersen SE, Raichle ME (1995) Activation of anterior right prefrontal cortex during semantic monitoring. Soc Neurosci Abstr 21:1441.

Martin A, Haxby JV, Lalonde FM, Wiggs CL, Ungerleider LG (1995) Discrete cortical regions associated with knowledge of color and knowledge of action. Science 270:102-105.

Mintun MA, Fox PT, Raichle ME (1989) A highly accurate method of localizing regions of neuronal activation in the human brain with positron emission tomography. J Cereb Blood Flow Metab 9:96-103.

Moscovitch M, Behrmann M, Winocur G (1994) Do PETS have long or short ears? Mental imagery and neuroimaging. Trends Neurosci 17:292-294.

Nyberg L, Tulving E, Habib R, Nilsson LG, Kapur S, Houle S, Cabeza R, McIntosh AR (1996) Functional brain maps of retrieval mode and recovery of episodic information. NeuroReport 7:249-252.

Petersen SE, Fiez JA (1993) The processing of single words studied with positron emission tomography. Annu Rev Neurosci 16:509-530.

Petersen SE, Fox PT, Posner MI, Mintun M, Raichle ME (1988) Positron emission tomographic studies of the cortical anatomy of singleword processing. Nature 331:585-589.

Petersen SE, Fox PT, Posner MI, Mintun M, Raichle ME (1989) Positron emission tomographic studies of the processing of single words. J Cognit Neurosci 1:153-170.

Petrides M, Pandya DN (1994) Comparative architectonic analysis of the human and the macaque frontal cortex. In: Handbook of neuropsychology, Vol 9 (Boller F, Grafman J, eds), pp 17-58. Amsterdam: Elsevier.

Petrides M, Alivisatos B, Evans AC (1995) Functional activation of the human ventrolateral frontal cortex during mnemonic retrieval of verbal information. Proc Natl Acad Sci USA 92:5803-5807.

Picard N, Strick PL (1996) Motor areas of the medial wall: a review of their location and functional activation. Cereb Cortex, in press.

Raczkowski D, Kalat JW, Nebes R (1974) Reliability and validity of some handedness questionnaire items. Neuropsycholgia 6:43-47.

Raichle ME (1987) Circulatory and metabolic correlates of brain function in normal humans. In: Handbook of physiology, the nervous system. V. Higher functions of the brain, Part 2 (Mountcastle VB, Plum F, eds), pp 643-674. Bethesda: American Physiological Society.

Raichle ME (1994) Studies of the prefrontal cortex of normal human subjects: contributions from modern imaging techniques. In: Motor and cognitive functions of the prefrontal cortex (Thierry A-M, Glowinski J, Goldman-Rakic PS, Christen Y, eds), pp 175-179. New York: Springer.

Raichle ME, Fiez JA, Videen TO, MacLeod AK, Pardo JV, Fox PT, Petersen SE (1994) Practice-related changes in human brain functional anatomy during non-motor learning. Cereb Cortex 4:8-26.

Rajkowska G, Goldman-Rakic PS (1995a) Cytoarchitectonic definition of prefrontal areas in the normal human cortex. I. Remapping of areas 9 and 46 using quantitative criteria. Cereb Cortex 5:307-322.
Rajkowska G, Goldman-Rakic PS (1995b) Cytoarchitectonic definition of prefrontal areas in the normal human cortex. II. Variability in locations of areas 9 and 46 and relationship to the Talairach coordinate system. Cereb Cortex 5:323-337.

Roland PE, Gulyás B (1995) Visual memory, visual imagery, and visual recognition of large field patterns by the human brain: functional anatomy by positron emission tomography. Cereb Cortex 5:79-93.

Schacter DL, Tulving ET (1994) Memory systems 94. Cambridge: MIT.

Schacter DL, Alpert NM, Savage CR, Rauch SL, Albert MS (1996) Conscious recollection and the human hippocampal formation: evidence from positron emission tomography. Proc Natl Acad Sci USA 93:321-325.

Shulman GL, Buckner RL, Corbetta M, Miezin FM, Raichle ME, Petersen SE (1996) Consistent blood flow decreases during active visual tasks relative to passive viewing. Submitted to 2nd International Conference on Human Brain Mapping.

Silbersweig DA, Stern E, Frith CD, Cahill C, Schnorr L, Grootoonk S, Spinks T, Clark J, Frackowiak RSJ, Jones T (1993) Detection of thirtysecond cognitive activations in single subjects with positron emission tomography: a new low-dose $\mathrm{H}_{2}{ }^{15} \mathrm{O}$ regional cerebral blood flow threedimensional imaging technique. J Cereb Blood Flow Metab 13:617-629.

Snodgrass G, Vanderwart M (1980) A standardized set of 260 pictures: norms for name agreement, image agreement, familiarity, and visual complexity. J Exp Psychol Hum Learn Mem 6:164-215.

Snyder AZ, Videen TO, Raichle ME (1994) MRI independent nonstereotaxic registration of PET images with a standard antomical atlas. Soc Neurosci Abstr 20:148.

Spinks TJ, Jones T, Bailey DL, Townsend DW, Grootoonk S, Bloomfield PM, Gilardi M-C, Casey ME, Sipe B, Reed J (1992) Physical performance of a positron tomograph for brain imaging with retractable septa. Physical and Medical Biology 8:1637-1655.

Squire LR, Ojemann JG, Miezin FM, Petersen SE, Videen TO, Raichle ME (1992) Activation of the hippocampus in normal humans: a functional anatomical study of memory. Proc Natl Acad Sci USA 89:1837-1841.

Swick D, Knight RT 1996 Is prefrontal cortex involved in cued recall? A neuropsychological test of PET findings. Neuropsychologia 34:1019-1028.

Talairach J, Tournoux P (1988) Co-planar stereotaxic atlas of the human brain. New York: Thieme.

Tulving E (1983) Elements of episodic memory. New York: Oxford UP. Tulving E (1985) How many memory systems are there? Am Psychol 40:385-398.

Tulving E, Kapur S, Markowitsch HJ, Craik FIM, Habib R, Houle S (1994a) Neuroanatomical correlates of retrieval in episodic memory: auditory sentence recognition. Proc Natl Acad Sci USA 91:2012-2015.

Tulving E, Kapur S, Craik FIM, Habib R, Houle S (1994b) Hemispheric encoding/retrieval asymmetry in episodic memory: positron emission tomography findings. Proc Natl Acad Sci USA 91:2016-2020.

Tversky B, Sherman T (1975) Pictures memory improves with longer on time and off time. J Exp Psychol Hum Learn Mem 104:114-118.

Wise R, Chollet F, Hadar U, Friston K, Hoffner E, Frackowiak RSJ (1991) Distribution of cortical neural networks involved in word comprehension and word retrieval. Brain 114:1803-1817. 